University of Nebraska - Lincoln

DigitalCommons@University of Nebraska - Lincoln

Investigations of the Ichthyofauna of

Nicaraguan Lakes

Papers in the Biological Sciences

1976

The Behavior and Ecology of Herotilapia multispinosa (Teleostei,

Cichlidae)

Jeffrey R. Baylis

Rockefeller University

Follow this and additional works at: https://digitalcommons.unl.edu/ichthynicar

Part of the Aquaculture and Fisheries Commons

Baylis, Jeffrey R., "The Behavior and Ecology of Herotilapia multispinosa (Teleostei, Cichlidae)" (1976). Investigations of the Ichthyofauna of Nicaraguan Lakes. 35.

https://digitalcommons.unl.edu/ichthynicar/35

This Article is brought to you for free and open access by the Papers in the Biological Sciences at DigitalCommons@University of Nebraska - Lincoln. It has been accepted for inclusion in Investigations of the Ichthyofauna of Nicaraguan Lakes by an authorized administrator of DigitalCommons@University of Nebraska Lincoln. 
Z. Tierpsychol., 34, 115-146 (1974)

(C) 1974 Verlag Paul Parey, Berlin und Hamburg

ISSN 0044-3573 / ASTM-Coden: ZETIAG

\author{
Museum of Vertebrate Zoology and Department of Zoology, \\ University of California, Berkeley, California
}

\title{
The Behavior and Ecology of Herotilapia multispinosa (Teleostei, Cichlidae)
}

\author{
By JEFFREY R. BAYLIS \\ With 4 figures
}

Received: 9. 12. 1972

\section{Introduction}

Because of their complex social behavior and the ease with which they can be manipulated, cichlid fishes have long been of special interest to the ethologist. However, most of the research into cichlid behavior has been on Old World species. The social behavior of New World species is different and deserves more study. This paper will describe the ethology of one of the Central American cichlids, Herotilapia multispinosa (GüNTHER).

A precondition to understanding the social behavior of a species is an understanding of its ecology (MARLER 1969). The combined behavioral and ecological study of an animal has been the ethological ideal, because only a thorough knowledge of the life history of the organism can tell us why, in an evolutionary sense, the animal behaves as it does. However, this is an ideal that is seldom realized in ethological studies of cichlid fishes.

I was fortunate to find in Herotilapia multispinosa an animal amenable to the classic ethological approach. By considering behavior in relation to natural history the adaptive significance of much of the behavior became more apparent. Actions that might otherwise have remained puzzling were clarified and integrated into a picture whose scope would have been more limited if ecology had not been considered. Aspects of cichlid behavior, whose significance was not previously appreciated, assumed new importance as a direct result of my opportunity to work in the field.

The fish

\section{Materials and Methods}

Herotilapia multispinosa is endemic to the Lake Managua/Lake Nicaragua/Río San Juan drainage complex of Nicaragua and Costa Rica. The species was described by GüNTHER (1869) in the genus Heros (= Cichlasoma). Pellegrin (1903) removed it from the Cichlasoma and placed it in the new, monotypic genus Herotilapia solely on the basis of tricuspid teeth. 
Since the invasion of cichlids into Central Anerica is recent and their radiation dramatic (MYERs 1966), the relationships among cichlids there is open to question. But there is little doubt that the closest 'relatives' of Herotilapia lie within Cichlasoma.

Herotilapia is not a large cichlid. The adult ô $\delta$ in this study averaged about $8 \mathrm{~cm}$ in standard length, while the $Q Q$ averaged $7 \mathrm{~cm}$. Nine of the 52 adults used were caught in Nicaragua and Costa Rica. Others were raised in the laboratory from stock obtained from local aquarists.

Aquaria

Four aquaria were used: Two had a capacity of 541 each, one 1521 and one 2601 (bottom $=98 \mathrm{~cm} \times 70 \mathrm{~cm}$ ). The bottom of each was covered with $3-5 \mathrm{~cm}$ of medium grade aquarium gravel. Split flower pots, rocks and plastic 'tents' provided hides for the fish. The rear and sides of the tanks were covered with cardboard.

Water

Tap water was used, with the addition of $5 \mathrm{~g} / \mathrm{l}$ of marine salt to buffer the $\mathrm{pH}(6.5-7.5)$ and provide hardness. Filtration was by inside box filters filled with dacron wool. The temperature was regulated at $28^{\circ} \pm 0.5^{\circ} \mathrm{C}$.

Light

Two 25-W warm-white flourescent tubes, $15 \mathrm{~cm}$ above the water surface, provided illumination in the largest tank. The smaller aquaria were each illuminated by two $25-\mathrm{W}$ incandescent lamps. All aquaria were on a $10 \mathrm{hrs}$. light $/ 14 \mathrm{hrs}$. dark photo-period.

Food

The fish received daily feedings of live adult Artemia salina (brine shrimp) plus a variety of dry foods. Fry received Artemia nauplii and powdered TetraMin.

Preobservational treatment

When not in the aquaria, the fish were held in a wire-mesh cage in a large, shallow outdoor pond. The water was filtered through sand, and maintained at $26^{\circ} \pm 1.0^{\circ} \mathrm{C}$. Fish in the pond were fed commercial trout chow twice daily.

Observational methods

Observations were made over a period of about 18 months. Groups of from 2 to 8 fish were placed into an aquarium at one time and observed up to 4 months. Data were obtained by direct observation, and recorded by writing or by speaking into a tape recorder. A videotape recorder, cine films and strobe-light still photography were also employed. Some data were recorded on Multiple Event Recorder. A hydrophone was used briefly to determine if sounds were associated with any of the action patterns. Field collections were made using a $6 \mathrm{~m} \times 1.3 \mathrm{~m}$ common sense seine with a $0.6 \mathrm{~cm}$ mesh.

\section{Natural History}

\section{Ecology}

Herotilapia is characteristically a fish of turbid and shallow waters. It occurs along the weedy margins of lakes, rivers and streams. The habitat where the species most typically survives and reproduces is the small ponds that are periodically flooded by rising waters from nearby lakes or rivers.

The lowlands of the Lake Nicaragua/Río San Juan drainage appear to be the center of distribution for the species, although it is also found in the Río Tempisque/Río Bebedero drainage of Costa Rica (W. Bussing pers. comm.). The range of the species may be more extensive, especially on the Atlantic coastal plain, but information from that region is sketchy.

Despite their species-rich radiation in Central America, most of the cichlid species there are rather generalized. However, the unique possession of tricuspid teeth by Herotilapia, implying a vegetarian diet, and the small adult size of the species, suggest trophic niche specialization.

Diet

As one might expect from its dentition and long gut, Herotilapia eats algae. Stomach contents of specimens from the field revealed almost entirely 
plant matter. The bulk of the food was a flocculent material consisting of simple algae and diatoms, probably scraped off the substrate. Larger filamentous algae and bits of higher plants (Heteranthera sp.) were also conspicuous. Numerous tiny scales were present in the guts of a few specimens, suggesting that small fish are occasional departures from the usual vegetarian fare.

Herotilapia is not restricted to plant material. Fish in the laboratory were catholic in their tastes. In addition to algae, they consumed large numbers of adult Artemia, insects, snails, leeches, fish of a suitably small size, and various commercial dry fish foods. That Herotilapia will eat animal food when it is available, even though an adequate supply of plant material is at hand, suggests Herotilapia is a facultative herbivore but an omnivore by preference. The restricted diet of the field-collected specimens probably results from item availability in their immediate habitat rather than choice.

Habitats season.

All collections were made in May of 1970, immediately prior to the start of the rainy

Herotilapia were seined from three localities: one in Nicaragua and two in Costa Rica. At the Río Ochomoga in Nicaragua and the Río Bebedero at Taboga, Costa Rica, the rivers were small shallow streams with quiet pools. At both localities large juvenile Herotilapia were taken; no adults, fry, or breeding Herotilapia were found.

The third locality was the Río Frío at Los Chiles, Costa Rica. The remainder of this section will be concerned solely with that locality. The Río Frío is a broad (ca. $50 \mathrm{~m}$ ) river. The water was turbid, and a fine silty mud covered the clay banks and the river bottom. The flat lowlands surrounding Los Chiles were rarely more than 3 or $4 \mathrm{~m}$ above the level of the river. In the rainy season the river overflows its banks and floods the surrounding countryside with shallow water (W. Bussing, G. H. MERAL, pers. comm.).

Piscivorous birds were common along the river banks, with the herons being especially well represented. Cranes and kingfishers were also present, as were large turtles, gars, tarpon, predatory catfishes, and, according to native reports, sharks. Predatory characins, cichlids, and other fishes actually collected with Herotilapia will be mentioned later.

Six sites were seined at Los Chiles; four from the river or tributaries connected to the river, and two from shallow swampy ponds well isolated from the river. Herotilapia were collected at two of the river sites and at both of the ponds.

The bottoms of the ponds consisted of mud and clay. The water was turbid and visibility was limited to a few $\mathrm{cm}$ at most. The surface was covered with floating aquatic plants (Azolla mexicana). Underwater vegetation consisted of Heteranthera sp., algae, and in the very shallow areas, grass hummocks. At both sites the maximum water depth was about $25 \mathrm{~cm}$ and the surface water temperature was $34^{\circ} \mathrm{C}, 5^{\circ}$ warmer than the river. One pond was about $15 \mathrm{~m}$ and the other about $60 \mathrm{~m}$ in diameter.

Herons and cranes were observed feeding in these ponds. Cattle also frequented both ponds and used them for drinking and wallowing, so much so that the pond bottoms were pocked with hoof prints.

Although Herotilapia occurs in bodies of water inhabited by a great many other fish species only 15 species were collected with Herotilapia. Of these 15 species only six occurred with Herotilapia in more than one collection: three characins (Astyanax fasciatus, Hyphessobrycon tortuguerae, Roeboides salvadoris), one poeciliid (Poecilia mexicana) and one cichlid (Cichlasoma managuense). Cichlasoma centrarchus was taken with Herotilapia in two of the collections.

The three characin species caught from Río Frío dominated the collection in numbers of individuals. All of the characins occurred in one of the two ponds as well as in the river. The three characins and the poeciliid are rarely found as individuals. They all tend to move in loose schools near the surface. They are probably not territorial, although this has not been investigated. All are capable of eating cichlid fry, but would pose no threat to juvenile or adult Herotilapia.

Cichlasoma managuense, a large predator, was ubiquitous with Herotilapia. While common in the river, C.managuense was a 'rare' species in the ponds, where it never exceeded $10 \mathrm{~cm}$ in total length; adult specimens taken from the river were much larger. Only four small specimens were collected from one pond, while the other yielded only one specimen. C. managuense was the only cichlid species besides Herotilapia that was collected from the ponds. 
Cicblasoma centrarchus was seined only from the river where it occurred in both collections containing Herotilapia. As its name implies, C.centrarchus bears a superficial resemblance to the sunfishes of North America. It is larger than Herotilapia and apparently more carnivorous in habits. Juveniles and adults were collected, and there was evidence of reproductive activity. This species occurred at all four of the river sites at Los Chiles.

Herotilapia multispinosa was caught at two of the river sites. At both, the habitat was the quiet weedy margin of the river bank. The water was shallow (less than $60 \mathrm{~cm}$ ) and the current minimal. There was an emergent vegetation of grasses. Although it was present in the river, Herotilapia was by no means a common. species there. It was apparently restricted to a single habitat type in the river, and there was no evidence of reproductive activity there.

Herotilapia was present in both ponds where it formed a conspicuous component of the fish fauna. Adults with reproductive color patterns, as well as fry and juveniles, were collected. Both ponds supported actively breeding populations.

Probably the most significant predators on Herotilapia in the pond habitat are the wading birds. This may explain the large number of dorsal and anal-fin spines that give Herotilapia its specific name, multispinosa. The characins, juveniles of $C$. managuense, and adult and juvenile Herotilapia can doubtless consume numbers of young Herotilapia less than $2 \mathrm{~cm}$ in length, but young of that size would still be defended by their parents. Parental care should minimize the effects of these latter sources of predation.

In the past William Bussing and Gerald Meral have collected at Los Chiles during the wet season. Both have seined one of the pond sites when it was connected to the river, and they also seined the surrounding flooded grasses. They found adult and large juvenile Herotilapia, but neither found any evidence of active breeding. Bussing (pers. comm.) has opined that Herotilapia is never dominant in large habitats, which agrees with my experience.

A comparison of the pond and river habitats would be appropriate at this point. The riverine habitat has two primary advantages over the pond habitat for a fish species. The first is permanence. The river is not likely to dry up, and is not as subject to environmental extremes and casual disruption as is a pond. The second advantage is dis persal. The river is essentially continuous throughout its length and presents no severe zoogeographical barriers to dispersal within its system.

The ponds offer their own advantages. They are far less diverse in fish species than the river, and would therefore offer few competitors. Large aquatic predators are lacking, thus removing this source of predation on adult fish. Wading birds are present, but these predators also frequent the margins of the river, and the floating vegetation of the ponds may make feeding there more difficult for them. The remaining predators (characins, small C. managuense) are too small to feed on anything but fry and the smallest juvenile cichlids, and of course these smaller predators are found in the river in larger numbers. Further, the strong current and heavy silt in the river make conditions poor for the growth of filamentous and encrusting algae, while the shallow ponds offer better conditions, including the concentration of nutrients as the ponds evaporate.

Another advantage the pond habitat has over the river for a cichlid species is the absence of interspecific competition for breeding sites. Ideal cichlid breeding habitats are probably rare in the river. A calm, quiet site, free from strong currents and shifting substrate is needed. When pond-like river locations were seined, large reproductively active $C$. managuense or C. centrarchus were found.

Since Herotilapia was the smallest cichlid species collected at Los Chiles, I doubt that it could compete successfully with the other cichlid species for breeding sites in the river. The ponds, however, are a marginal habitat for most other cichlids. The shallowness of the ponds makes small size mandatory for a fish. This shallowness also makes them susceptible to rapid fluctuations in temperature. Large amounts of rotting vegetation in the ponds produce hypoxic conditions, which Herotilapia has been shown to tolerate in the course 
of a physiological ecology laboratory exercise here at Berkeley. By the end of the dry season Herotilapia shares the ponds with only one other cichlid, the juvenile $C$. managuense. The competition for breeding sites within the ponds is therefore exclusively intraspecific.

In conclusion, these ponds may be thought of as 'islands'. If we apply the model of MACARTHUR and WILsON (1967) to this situation we would expect to see success in the ponds as a function of vagility (probability of immigration) and tolerance of physiological stress (probability of extinction). Actually, only Poecilia mexicana and Herotilapia may be considered 'true' colonizers of the ponds, since only these two species have been shown to maintain breeding populations there. If Herotilapia is the 'good colonizer' it appears to be, we would expect to observe specific adaptations in its life history and behaviour patterns that would give it an advantage as a colonizing species (LEWONTIN 1965).

\section{Life History}

Because of the evidence of reproductive activity at Los Chiles, my description of the life history pattern of Herotilapia is based almost entirely on data and personal observations from that location. The model that follows, therefore, is speculation based on scanty evidence. It is nonetheless accurate in its essential features. It is also consistent with laboratory observations on the behavior of the fish as well as with the field data on its ecology.

Herotilapia breeds in the ponds during the dry season. Large numbers of juveniles and many adults are present there by the end of the dry season. As the river floods the ponds, the Herotilapia move out over the flooded grasslands in small schools. There was no apparent breeding taking place while the ponds were flooded and connected to the river, even though many adult Herotilapia were present in the collections of Bussing and Meral. As the waters recede the fish remain in pockets and/or actively swim upstream into the draining fields. Some of these areas become isolated from the river and eventually dry up, but many persist as ponds until the next rainy season. The enduring ponds are where Herotilapia actively breed, and these are the centers of dispersal. There is always a peripheral population in the river but it is not actively reproducing. Some pairs of Herotilapia probably reproduce in the river, but the proportion must be small. The ponds act as a 'privileged sanctuary' that the species can exploit without having to compete with other cichlids for food and breeding sites. With the arrival of the rainy season the river is once again used for dispersion.

This life-history pattern gives the species the advantages of living in the river plus the advantages of living in the ponds. The river population acts as a 'buffer' against an excessively dry year that might destroy the pond populations.

Herotilapia is therefore an opportunistic species in the classic sense, “... species which often become extinct locally and which rely on dispersal rather than on competitive ability", (vAN VALEN 1971). Much of the above applies to Poecilia mexicana as well, which also seems to use the ponds as a 'refuge'.

Both $P$. mexicana and $H$. multispinosa are facultative herbivores, a type of diet that would give them an advantage in exploiting habitats of low diversity. The small size and precocious development of both may be specific adaptations to exploiting the 'island' habitat of the pond. Later I will describe behavioral adaptations which give the species a high vagility and a rate of reproduction largely independent of the density of the breeding population. 


\section{Feeding Behavior}

The feeding methods of Herotilapia are as generalized as its diet. There are two methods of feeding on plant material. In one, the mouth is pressed against the substrate and encrusting algae is rasped off with a series of bites, while swimming motions prevent the fish from being pushed away. A similar feeding behavior was described for Tilapia natalensis $(=T$. mossambica) by BAERENDS and BAERENDS-VAN ROON (1950).

Herotilapia also feeds on filamentous algae and higher aquatic plants. The filaments or leaves are sucked into the mouth, and then bitten off by a combination of biting and tugging as the fish back away.

When feeding in detritus on the bottom of a tank, a Herotilapia will settle with its ventral body surface touching the substrate. It fans forward vigorously with the pectoral fins while swimming motions hold the fish stationary. This behavior is virtually identical to the action pattern 'Plowing' described by BARLOw (1961), except that substrate material is rarely taken into the mouth prior to fanning, unlike Cyprinodon macularius. After Plowing, the fish darts forward, picks food items out of the swirling mulm and inspects the newly exposed substrate.

When feeding over a bare gravel bottom, Herotilapia does not Plow. Instead, a mouthful of gravel is bitten out of the substrate, churned in the mouth with chewing motions, and then spit out, presumably minus edible particles.

When feeding on animal food swimming in midwater (such as adult brine shrimp), the fish 'fixes' on an individual food item from a distance of several centimeters and then darts up to engulf it. There is no ' $S$ ' curving for a 'strike' as there is in some predatory fishes.

Food floating on the surface of the tank is also 'fixed' on from a distance. The fish darts to the surface, seizes the item, and then darts back down to the middle of the tank. It does not remain at the surface and continue to feed as would a Tilapia or a goldfish. Rather, the food is obtained in a series of quick darts to the surface and back.

The fry eat in a different manner. Once they become free-swimming they feed by 'grazing' over surfaces covered with an algae 'Auf wuchs'. They move predominantly up vertical surfaces with their heads oriented normal to the plane while they pick at the substrate. Their eyes are highly mobile and are mounted well forward on the head. This gives the fry a remarkable degree of binocular vision, reminiscent of small puffer fish. They also feed in a manner similar to a puffer, hovering and picking at specific food items. Their food probably consists of small crustaceans, nematodes, rotifers and bits of algae.

The fry are positively phototactic in weak light. This would have obvious advantages in obtaining planktonic food.

When feeding on prey in midwater (brineshrimp nauplii), the fry show a specific behavior pattern not shown by the adults. The fry fix on an individual nauplius, assume an ' $S$ ' curve, and then strike with a sudden lunge. This pattern of feeding disappears in juveniles, and I have never seen it in the adult feeding behavior. Bergmann (1968) observed the same behavior in Pterophyllum $(=$ Plataxoides) scalare fry, and similarly reported that it disappears early in ontogeny. 


\section{Fright Behavior}

A frightened adult Herotilapia assumes the Pale color pattern. This pattern has some of the important features usually associated with patterns used for concealment (see Color Patterns).

When presented with a conspicuous fear-producing stimulus (i. e., a net) Herotilapia shows oriented flight. It tries a) to avoid the stimulus, and b) to place some object between itself and the stimulus. In a deep tank the flight is always toward the bottom and away. In a shallow tank, the fish may dart to the surface and jump to avoid pursuit.

Once shelter is achieved, the fish comes to an abrupt halt. All fins are spread, and the spinous portions of the dorsal and anal fins are fully erect. The fish may hover with rapid beats of the pectoral fins. The entire aspect of the fish is one of extreme tension.

Freezing is a common response, especially when the fear stimulus is not specific (such as transfering fish to a new tank). The fish darts to a corner of the tank or a shelter, and stops all movement. All fins are fully erected, but not even the pectoral fins are in motion. The fish lies on the bottom propped up by its fins. Orientation may be lost with respect to the substrate, but the fish does not make an effort to correct its leaning posture.

As time passes with no additional fear stimuli, the fish starts to hover with fins erect. If there are no more alarming developments, it will then start to move around the tank with fins spread, progressing by short darts and quick stops interspaced with hovering.

The fish seems to try to keep the fright stimulus in view. It often hides with the head and one eye exposed. The eye tracks the offending object.

When more than one fish is present in the tank, aggregating occurs. This is more than just a result of several fish hiding in the same shelter. Once the fish have gotten over their initial freezing response, they tend to move as a single group. This generally starts out as a smaller group which individuals join as it moves cautiously around the tank.

The reaction of fry to a fear stimulus is dramatic. The first reaction is flight away from the stimulus and down toward the substrate. This is followed immediately by oriented flight to the densest part of the fry school. Thus the net result of disturbing a school of fry in a tank is that a loose, dispersed school becomes a dense compact school near the bottom. If the parents are present, the same reaction occurs, except that the fry bunch up directly under the parents. This is as much due to actions on the part of the parents as it is to the responses of the fry.

\section{Visual Displays}

The visual displays of cichlid fishes may be rendered into two categories: 1) the Signal Action Pattern; and 2) the Color Pattern. This division is not entirely artificial, because it can be argued that the color pattern and the action pattern carry different types of 'messages' (SMITH 1969). Where the term 'Display' is used in this paper, it refers to the Signal Action Pattern together with a specified Color Pattern. The Display is designated by the name of its principal Signal Action Pattern, followed by the word 'Display' (for example: Frontal Display).

\section{Signal Action Patterns}

I will not attempt to describe all the Modal Action Patterns (BARLow 1968) of Herotilapia. I refer the reader to the comprehensive work of BAERENDS 
and BAERENDS-vAN Roon (1950) on cichlid behavior for general descriptions of action patterns characterizing Cichlasoma not described here. Only the Modal Action Patterns (MAPs) associated with visual communication will be considered.

Communication among cichlid fishes obviously entails more than visual cues, although this seems to be the most important modality. The emphasis, therefore, will be on visual communication. When relevant, the probable role of other sensory channels in a Display Pattern will be discussed.

I define a Signal Action Pattern as a Modal Action Pattern with a communicatory function. If, given the context, I could predict with reasonable accuracy the behavior of the 'receiver' subsequent to the performance of a given act by the 'sender', then I assumed communication had occurred. 'Signal value' was inferred from the context and the nature of the actual acts performed by the two participants.

The following list of Herotilapia Signal Action Patterns contains the signals I could most easily recognize, categorize and observe. The terminology follows BAERENDS and BAERENDS-VAN ROoN (1950). When differences in nomenclature occur the term employed by BAERENDS and BAERENDS-VAN ROON will be given in parentheses. Where action patterns are new or sufficiently different to warrant, a short description is given.

I have divided the Signal Action Patterns into four categories, based on the orientation of the act and the nature of the act performed.

1) Broadcast Orientation: The 'sender' assumes no special orientation with respect to a specific 'receiver', although it may assume a specific orientation relative to a site or location within the tank.

Standing. The fish hovers with all fins fully spread.

2) Site Orientation: The 'sender' is oriented with respect to a specific site or location within the tank, and may orient relative to a specific 'receiver' as well.

Digging. While digging is not usually considered to have a signal function, it seems to serve an important signal role in Herotilapia. In addition to the visual aspects of the act, a loud burst of white noise accompanies each 'bite' into the gravel substrate.

Nipping (Nipping off a substrate). This is a highly 'formalized' activity, quite different from feeding off a substrate. Much noise is produced. It is a strident, scratchy sound apparently made by the teeth. This sound also accompanies feeding activity.

Skimming. This action is more similar to Plowing or Skim-Fanning (see Section VII) than it is to the spawning movements. The entire ventral portion of the body is kept parallel to the substrate and just touching it, while the pectoral fins fan forward, their lower margins brushing the substrate.

3) Individual Orientation: The sender is specifically oriented to the receiver. The Signal Pattern is therefore 'addressed' to an individual.

Pitch-up (Attitude of inferiorism). Fish is head up with the body about $30^{\circ}$ above the horizontal; body is tilted toward the receiver.

Jerking. BAERENDS and BAERENDS-VAN ROoN stated that Jerking and Quivering have the same 'meaning'. They were observed to grade into each other, and were therefore classed as a single action pattern. In Herotilapia, however, the two movements occur in different contexts, and do not seem to carry the same message. They are easily identified as separate action patterns, although they can grade into each other. Jerking is a large amplitude twitching of the head to one side. A sound is occasionally generated during this action pattern. It is a low, quiet 'purr'.

Quivering. Quivering is a series of rapidly repeated twiches that involve the entire body. The amplitude of each twitch of the head is low. During a violent bout of quivering the fish may lose orientation with respect to the substrate. At such times this action pattern resembles a piscian epilepsy. Quivering commonly occurs together with Digging and Nipping, as well as occurring alone. The 'purr' sound is occasionally emitted during Quivering. 
Lateral. The median and pelvic fins are fully erected, although this may not be true of their spinous portions during an extreme manifestation. Also during intense encounters, the body may assume a curve or ' $S$ ' shape, while the mouth is opened wide and the head is turned toward the opponent. This may be accompanied by weak forward locomotion derived from the pectoral fins.

Exaggerated swimming. The fish makes typical forward swimming undulations, but the amplitude is greatly exaggerated. Forward progress may be slowed due to braking by the pectoral fins. The fins are all spread, but the spinous portions of the dorsal, anal and pelvic fins may not be fully erect.

Tailbeat. The Tailbeats are directed toward the 'receiver'. The mouth may be fully opened during an intense manifestation.

Stationary swimming (Swimming on the spot). Violent forward swimming motions are made while the pectoral fins thrust forward, consequently the fish remains stationary or moves slowly forward. It of ten occurs together with Frontal.

Frontal. The body frequently assumes an ' $S$ ' shape. In the most complete form the mouth is fully opened. Even in the least intense manifestation the gill covers are lifted and the branchiostegal membrane is erected. The fish is oriented with its head toward the 'receiver'.

Snapping. The fish orients with its head down, at an angle of about $45^{\circ}$ with respect to the bottom, and facing the 'receiver'. It is similar to intense Frontal, except that the mouth is rapidly opened and shut. A loud 'popping' sound is heard at this time. This action pattern may also occur during Jawlock, when it is again accompanied by the popping sound.

Jolting. The median fins may or may not be fully erected; the pelvic fins are folded up against the body. The head is jerked sideways and a rapid locomotory wave passes along the body. The pelvic and median fins are snapped erect as the pectoral fins brake the forward motion. The pelvic fins are then slowly folded back against the body. The action pattern is usually repeated several times, often with the fish backing away, head down, facing the of fending stimulus.

4) Overt: These acts may not be Signal Action Patterns in the strict sense since they are not symbolic acts of intention, but are overt acts. However, they do influence the behavior of the recipient, and are Signal Action Patterns in that sense.

Jawlock (Mouth-fighting). The pushing and pulling described for other cichlid species is lacking. There is little or no change of relative position during Jawlock. The Jawlock is usually broken with a pronounced sideways jerk of the head. The 'victor' appears to be the fish that grasps the opponent's upper jaw. This may be a function of the greater fragility of the teleost upper jaw relative to the lower jaw, or the inability of the opponent to control the jaws for respiratory purposes while the upper is so grasped.

Ramming (Butting). The fish swims rapidly toward its opponent and strikes it on the side with its head. The mouth may be open or closed, or a bite may be delivered during this behavior.

Pushing. Similar to Ramming, except it is much slower and less violent. The mouth is open, and is used to push the side of the receiver.

Biting. A portion of the opponent's anatomy is taken into the mouth, and the mouth is then closed, frequently with a jerking motion of the head.

Chasing. The recipient is pursued with rapid swimming movements. The pursuer frequently appears to be swimming deliberately slower than the pursued.

Special action patterns, such as those associated with spawning or aerating the eggs, will be discussed in section VII. Those acts occur in unique contexts, and are most profitably discussed in their appropriate settings.

\section{Color Patterns}

Although chemical (KüHmE 1963, MYrberg 1964, 1966) and auditory (MYrBERG 1965) communication have been demonstrated in cichlid fishes, the assessment of NoBLE and CuRTIS (1939) that vision is the most important modality for social behavior in cichlid fishes stands unchallenged. This is not surprising, since the advantages of visual communication for schooling or territorial behavior for a diurnal fish are obvious.

Noble and Curtis (1939) asserted that the 'nuptial' coloration of Hemichromis bimaculatus serves not as 'adornment', but only renders the movements 
of the fish more conspicuous. However, BARLow $(1962,1967)$ observed that in Badis badis the color patterns themselves have signal value. In a quantitative study on the cichlid fish Haplochromis burtoni, LEONG (1969) demonstrated the independent signal value of two of the fish's markings. These studies, correlating changes in behavior with essentially static visual displays, give ample evidence that color patterns can be signals in themselves as well as rendering kinetic displays more conspicuous.

In a paper on Lebistes (= Poecilia) reticulatus, BAERENDS et al. (1955) discussed the role of dynamic color patterns of the $\hat{\delta}$ as an indicator of its internal state. The many color patterns of Badis badis were described as correlates of the motivational state of the animal by BARLOw (1962). The reproductive color patterns of Tilapia mossambica were discussed in relationship to their associated behavior by NeIL (1964). Most of the information on coloration in cichlid fishes concerns general observations on the color patterns that accompany certain classes of behavior. The following study on Herotilapia coloration is patterned after the work of BARLOW (1963) on Badis badis, and hence is descriptive rather than quantitative.

Herotilapia can undergo rapid changes in coloration and can exhibit a variety of color patterns, although it lacks the versatility of Badis badis. Herotilapia demonstrates both the morphological and physiological color changes that ODIORNE (1957) described for fishes. The single morphological color change I have observed is the assumption (or loss) of the conspicuous 'nuptial' coloration with reproductive activity. This involves a change in the ground color of the fish and is probably under hormonal control. Overlaying this ground color is a system of melanophores and iridophores which is probably under a combination of neural and hormonal control. These are responsible for all rapid color changes which exhibit the characteristics of physiological color changes.

\section{Elements of the Color Patterns}

The color patterns of Herotilapia may be broken down into a series of basic elements (Fig. 1). These tend to act as functional units and are somewhat independent of each other. The contraction that follows the name of some elements is the designation by which the element will be referred to in the description of the color patterns.

Ground color (Grnd $\mathrm{Clr}$ ). The Ground Color ranges from light muddy brown to bright yellow-gold. The fish is usually counter shaded (lighter ventrally).

Lateral stripe (Lat Str). The Lateral Stripe may be entirely absent, light brown, or jet black. It is generally well defined, with sharp borders. It is composed of two sub-elements, the Solid Stripe and the Spots.

1. Solid stripe (Sol Str). The Solid Stripe consists of about four fused spots, the most posterior spot being the largest and most distinctly separate (Spt 6). Sol Str begins on the gill cover just behind the eye and continues posteriorly until it reaches the longitudinal midpoint of the body.

2. Spots (Spts). The Spots are five in number, not counting the Sol Str. The largest and most nearly circular of these is the most anterior (Spt 5). The rest are irregular in shape, except for the last one (Spt 1). This spot is situated on the caudal base. It is small and distinctly lens shaped.

Eye. The Eye might almost be considered the first element of the Lat Str; it is large with a prominent black pupil. The iris ranges from muddy dark brown to bright yellow. When yellow the iris is iridescent and highly reflective; then it is the most conspicuous single marking on the fish.

Bars (Brs). The Bars are 11 in number. They do not extend onto the fins. As may be seen from the diagram (Fig. 1), paired bars (which of ten fuse to form single bars) have been counted as one bar. There are two sub-elements to the bar system; the Dorsal Bars and the Ventral Bars. 

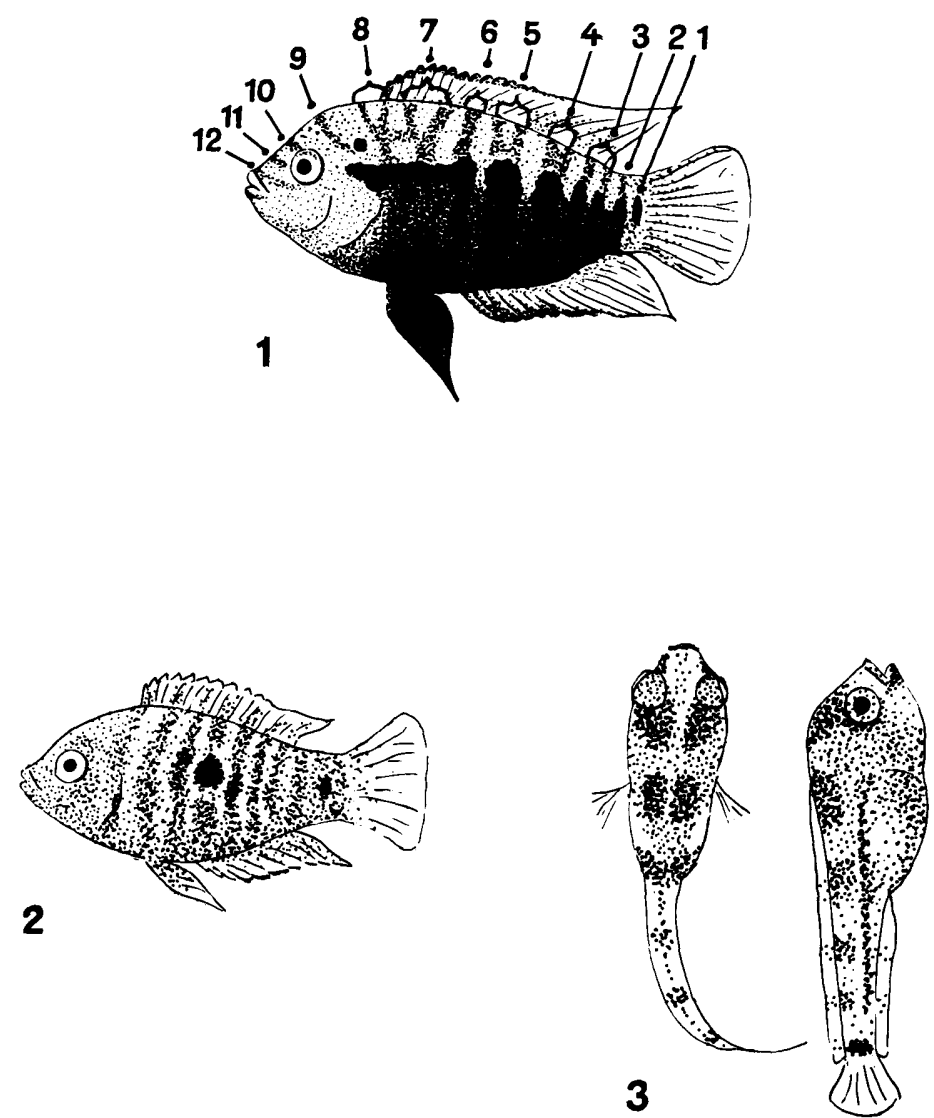

Fig. 1: The elements of the Herotilapia color patterns.

All serially repeating elements are designated by the number of the appropriate Dorsal Bar Fig. 2: Ocellated Pattern

Fig. 3: Fry Pattern

1. Dorsal bars (Dor Brs). The Dorsal Bars may be absent, or present as indistinct light brown areas, or dark and distinct. They are rarely completely black. Dor Brs 7 through 12 are the anterior Dor Brs. Dor Brs 2 through 6 are the posterior Dor Brs. These two groupings may behave as separate units or as a single unit. At its fullest expression each of the Dor Brs 2 trough 8 terminates at a specific component Spt of the Lat Str.

2. Ventral bars (Vent Brs). The Ventral Bars are extensions of the posterior Dor Brs onto the lower half of the body. They are associated with Spts 2 through 6 or the Lat Str. The Vent Brs may be lacking completely, light brown, or jet black. They may broaden and fuse, turning the entire ventral portion of the fish black.

Ocellus (Ocl). The Ocellus is a small circular spot located one diameter of the orbit above and behind the eye. It is approximately the diameter of the pupil in size. It may be absent, faint brown, or jet black. It may fuse with Dor $\mathrm{Br} 9$. Occasionally it is surrounded by a 'halo' lighter than the dorsal Grnd Clr.

Fins. Herotilapia has five sets of fins, the Dorsal, Caudal, Anal, Pectoral, and Pelvic fins. The Pectoral fins are always transparent and usually colorless, although they may be lightly pigmented. The Pelvic fins may be colorless, the same color as the Grnd Clr, or jet black. The Dorsal, Caudal and Anal fin may all be colorless or only slightly pigmented, and transparent; they may also take on the body Grnd Clr and lose their transparency. The Dorsal, Anal and Pelvic fins occasionally have black pigmentation edging their spinous portions; then there are blue highlights on these regions. 


\section{Typical Manifestations of the Color Patterns}

The markings described in the preceding section could theoretically occur in a large number of combinations of one or more elements. Instead, the elements occur only in a small number of specific combinations which are the characteristic color patterns of Herotilapia.
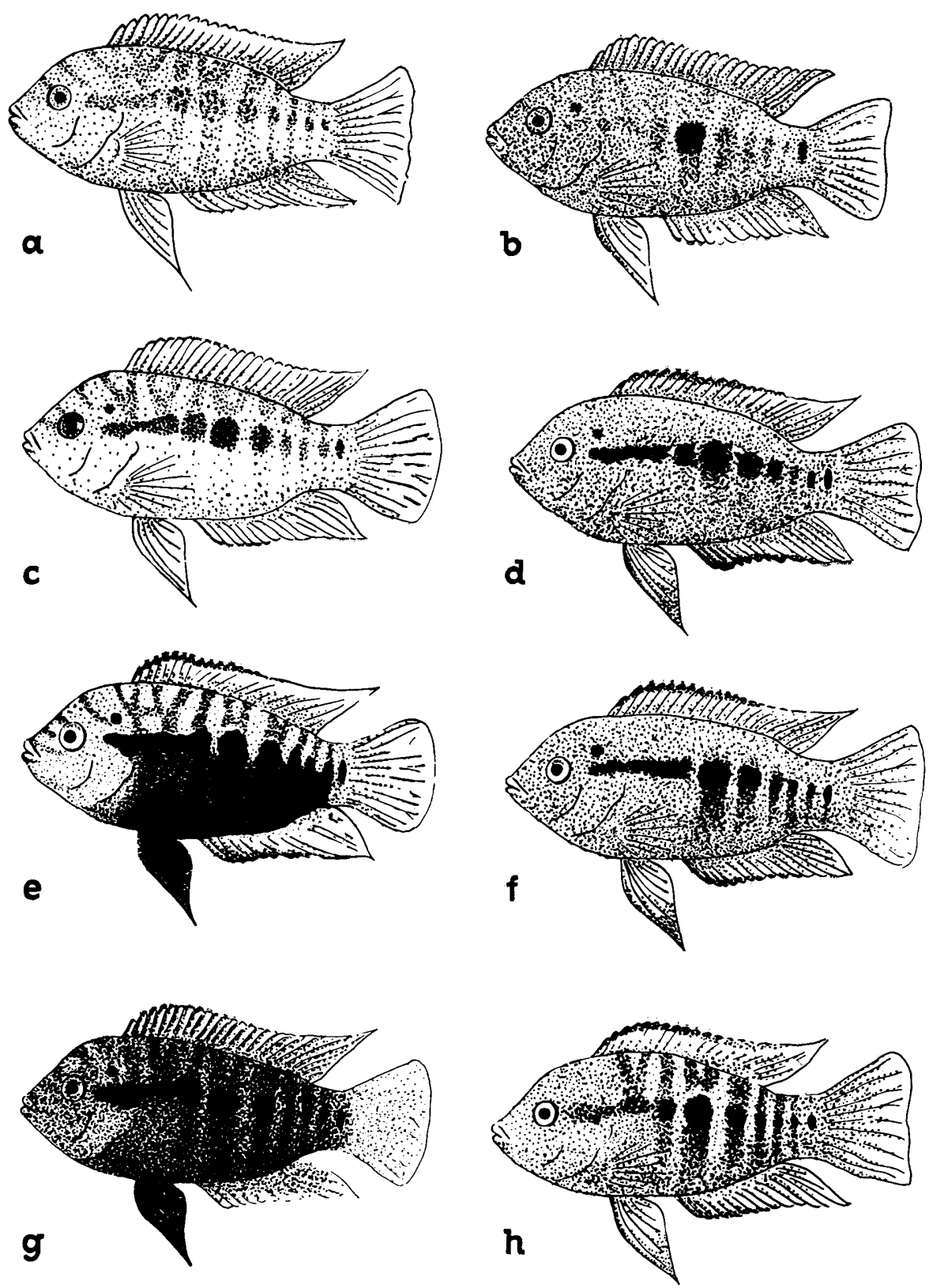

Fig. 4: Adult color patterns: a. Neutral, b. Two Spot, c. Pale, d. Stripe, e. Mitschattierung, f. Shaded Spots, g. Dark, h. Barred 
Many of these color patterns change rapidly and grade continuously into one another. They are modes or norms of response in a graded system rather than rigid units. The concept of Typical Manifestation (BARLOw 1963) was used to delimit these modes while avoiding assumptions about the motivational state and its relative strength.

The behavioral context in which each pattern was typically observed follows immediately after each description.

Neutral. Grnd $\mathrm{Cl}$ is pale brown or pale yellow-brown dorsally. Iris same as dorsal body; ventral coloration silvery white; Dor Brs very faint if present; Lat Str faint or entirely absent; Fins transparent (Fig. 4a).

Adults foraging alone.

Two spot. Grnd Clr as in Neutral. Eye as dorsal body, but more reflective. Lat Str faint, except for Spts 1 and 5, which are black and well defined. These two Spts are often surrounded by a reflective pale area. Spts 2,4 , and 6 may also be present, but are fainter than Spts 1 and 5 (Fig. 4b).

Schooling or aggregating fish.

Pale. Dorsal body extremely pale; iris dark brown and unreflective; ventral body white. Dor Brs brown and diffuse; Lat Str dark but not jet black, Spts tend to run together. Fins transparent (Fig. 4c).

Fish lying motionless on bottom after flight; fish fleeing from predator.

Stripe. Grnd $\mathrm{Clr}$ bright yellow-gold, extending onto median fins. Iris as $\mathrm{Grnd} \mathrm{Cl}$ and highly reflective. Posterior ventral surface of body may have alternate rows of pale blue scales. Lat Str and Ocl are jet black and sharply defined. Dorsal and anal fins edged with black; blue highlights on spinous portions. Spine and first ray of pelvic fins black (Fig. 4d).

Territorial $\hat{\delta} \hat{\delta} ;$; $q \underline{+}$ with ripe ovaries; courting or paired fish; parental adults away from fry or eggs.

Shaded Spots. All elements as in Stripe except that ventral posterior quarter is white. Also Vent Brs extend down from Spts 2 through 5 of the Lat Str, but may not reach ventral margin of body. Vent Br 5 is most prominent Bar. Posterior Dor Brs associated with these Spts may also be present. Pelvic fins dark (Fig. 4f).

Territorial $\hat{\delta} \hat{\sigma}$ in aggressive encounters of moderate intensity; paired $q$ 우 or $q$ 우 with ripe ovaries entering a $\delta$ 's territory; parental fish guarding eggs or fry.

Barred. Grnd Clr and Eye as in Stripe. Ocl and Sol Str portion of Lat Str are very pale or absent. Spts portion of Lat Str bladk. Brs 2 through 6 very dark. Areas between Brs pale and reflective. Pelvic fins dark (Fig. 4h).

Actively fighting $\hat{o} \hat{o}$ during intense aggressive encounter.

Mitschattierung (Term suggested by ALBRECHT [1962] for 'reverse countershading'). All elements as in Stripe. In addition: Dor Brs narrow and well defined; Vent Brs broad and very dark, fusing with the Lat Str to turn most of ventral body surface black. Pelvic fins and spinous portion of anal fin are black. Dorsal fin darker than the body Grnd Clr (Fig. 4e). Parental fish.

Dark. Iris very dark and unreflective. All Brs and Lat Str very dark and broad. Except for some light spaces in between Brs, fish is black all over (Fig. $\mathbf{4 g}$ ).

Subordinate fish severely attacked and chased when escape is impossible, as in a small aquarium (rarely observed).

The following two patterns were seen only on fry or juveniles. Since the fry and juveniles showed little variation in color pattern, they are described here separately from the adult color patterns.

Ocellated. Grnd $\mathrm{Cl}$ silvery and translucent. Iris as $\mathrm{Grnd} \mathrm{Cl}$ r and reflective. Spots 1 and 5 very dark; both bracketed by highly reflective silvery areas. Bars 2 through 6 present and complete (Fig. 2).

As described from juvenile $20 \mathrm{~mm}$ long and four weeks free swimming. This pattern was observed only on juveniles and older fry.

Fry. Body translucent. Black mark from lower jaw to eye. Black spot over each eye, and black spot above and behind each eye. They do not join across the dorsal median. Bladk spot on each side of dorsal body surface in front of dorsal-fin insertion, extending back to dorsal fin where they join. Split Head color pattern (BARLow 1967). Three more spots in sequence on dorsal base. Solid lateral stripe with large spot in the middle, terminating in 
straight vertical bar. Bar on caudal base, with spot (surrounded by silvery background) contained in concave side. Black on portion of anal base (Fig. 3 ):

As described from fry $7 \mathrm{~mm}$ long and 15 days free swimming. Observed only in fry.

\section{Rate of Change and Origins of Color Change}

The different elements of the color patterns vary in the speed that they can appear. The assumption or loss of the yellow ground color associated with the Stripe pattern takes several days. In contrast, Mitschattierung can be lost or gained in $10 \mathrm{sec}$, although it involves almost as much of the total body surface. The Pale pattern is faster yet, appearing within $2 \mathrm{sec}$. In general the markings produced by the melanophore and iridophore systems overlaying the ground color can appear or disappear rapidly, while the ground-color change requires more time.

Some of the elements do not suddenly appear in their entirety, but emerge gradually, with definite origins and indistinct stopping points. The anterior Dorsal Bars may originate either dorsally or as dorsal extensions of the Spots. The Ventral Bars always originate as ventral extensions of the Spots.

\section{Sexual Differences}

All of the color patterns exhibited by the $\delta$ are also expressed by the $q$, with the exception of the Barred pattern. A $q$ in Stripe pattern tends to be lighter ventrally than a similarly patterned $\delta$. A $q$ shows the Shaded Spots pattern more often during courtship than a of does. There is much overlap, however, between the sexes and a great deal of individual variation is present. Sexual differences in coloration involve intensity of expression rather than dissimilarities of basic color pattern.

There are morphological differences in external anatomy between the $\delta$ and $q$. The male Herotilapia is not as deep bodied relative to length as the $q$. The s's dorsal and anal fins are longer and more pointed, and the first ray of his pelvic fins is proportionately longer than the o's. The $\delta$ may have a small nuchal hump which gives him the steeper forehead profile. The $q$ of a mated pair is usually only about $3 / 4$ the weight of her mate.

The above characteristics are not definitive. Many $\delta \hat{\delta}$ do not develop the nuchal hump until after pair formation or spawning. Old, large $\$ q$ of ten have the external appearance of $\hat{\delta} \hat{\delta}$. Young adults spawning for the first time also show little or no discernable external differences between $\delta \hat{\delta}$ and $q+$. The extreme sexual dimorphism in coloration and morphology that characterizes many other cichlids species is largely absent. It takes a trained eye to distinguish a $\delta$ Herotilapia from a ?

Comments

\section{A. Ontogeny of the color patterns}

Precursors of many of the elements of the adult color patterns may be discerned in the Fry pattern. The future Dorsal Bars and the Lateral Stripe are present as separate systems. Spot 1, Spot 5 and Bar 2 are already well developed. Most of the elements of the adult patterns are derived by fissioning and further development of the elements of the Fry pattern. BAERENDS and BAERENDSVAN Roon (1950) have described this process for several other cichlid species.

\section{B. Functional aspects of the color patterns}

The color patterns of most animal species may be divided into two categories on the basis of their probable functions: Concealment, in which the function of the color pattern is to render the animal inconspicuous; and 
Advertisement, in which the function of the color pattern is to render the animal conspicuous (COTT 1957). The assignment of a color pattern to one of these two categories may be arbitrary, because a single color pattern can contain markings that are concealing and markings that are advertising. Further, a color pattern may be conspicuous when viewed close up and concealing when viewed from a greater distance (COTT 1957). In spite of these difficulties most of the color patterns of Herotilapia can be assigned to one or the other category with reasonable confidence.

\section{Concealment:}

Color patterns used for concealment generally have one or more of the following characteristics in common (Сотт 1957):

a. Variable color resemblance to the environment (background matching).

b. Obliterative countershading (ventral surface lighter than dorsal to eliminate shadow effects).

c. Disruptive coloration (markings that interrupt and/or draw eye away from body profile).

d. Concealment of appendages (fins) and conspicuous features (eyes).

Three of the Herotilapia color patterns have one or more of these characteristics. The patterns Neutral and Pale have a light body Ground Color which would tend to take on the color of the turbid water in which the fish lives (LURIA and KINNEY 1970).

Obliterative countershading enhances this effect. The addition of the Dorsal Bars element in the Pale pattern disrupts the body profile and tends to conceal the eyes (BARLOw 1972).

The Fry pattern also has a concealing function. The dark patches on the head of a 15-day old fry are interrupted as they cross the dorsal surface of the head. This is the Split Head color pattern, as in the leaf fish Polycentrus schomburgkii. This color pattern has valuable properties for concealment, and it is common to several species of predatory fishes (BARLOw 1967).

Concealment from potential predators is probably the primary role of the patterns Neutral and Pale. The Pale pattern is shown when a fish is experiencing extreme fright, and is not feeding at all. While foraging fish may show the Neutral Pattern, the manner in which they feed does not suggest concealment from prey items. The fish do not lurk or stalk, but move along slowly while they pick at the substrate.

Concealment from predators probably has not played an important role in the evolution of the Fry pattern. The fry show this pattern when they are in a large school that is defended by their parents. The feeding behavior of the fry suggests that concealment from their prey has played the primary role. The fry commonly feed on small invertebrates by moving up a vertical surface and picking at the substrate. The splithead pattern would conceal them from potential prey further up the slope.

This color pattern occurs on the fry of Cichlasoma friedrichstablii, C. labiatum, and several other species of Central American cichlid species in addition to Herotilapia. This pattern is an important general adaptation, and not just a developmental precursor of adult markings.

\section{Advertising:}

Color patterns used for advertising also have certain characteristics in common (CotT 1957, Hamilton ms.): 
a. Elements composed of pure colors.

b. Sharp, abrupt borders between contrasting elements.

c. 'Outlining' of markings to render them conspicuous (ocelli).

d. Reverse countershading (emphasis of shadow effects; SüfFERT 1932, Albrecht 1962).

e. Conspicuous markings on appendages or moving portions of the body (emphasis of motion).

Six Herotilapia color patterns have the characteristics of advertising patterns.

The Two Spot and Ocellated patterns are much alike. The Spots 1 and 5 are sharp bordered, and they are accented by a light surrounding field.

Bars 2 through 6 of the Barred pattern are accented by the light areas between the bars. The contrast rich light-dark pattern that results makes the movements of the fish highly conspicuous.

In both the Stripe and the Shaded Spots patterns the pure yellow-gold Ground Color is contrasted with the sharply defined black markings of the Lateral Stripe system. The iris makes the Eye conspicuous. The Eye is emphasized by the Lateral Stripe, which starts just behind the eye, rather than running throught it (BARLOW 1972).

The large areas of jet black which contrast sharply with the yellow-gold Ground Color make Mitschattierung an extraordinarily conspicuous pattern. The dramatic markings are reminiscent of the aposematic color patterns of hymenopteran insects.

The Dark pattern does not have the exclusive characteristics of either advertising or concealing coloration. This pattern could be either an attempt to match the dark background of the corner in which the fish is cowering, or it could be an appeasement signal. However, since it was only observed under extremely artificial circumstances I will dismiss this pattern as an artifact of the situation rather than treating it as a 'real' color pattern. The stress situation in which it occurred suggests that this pattern represents abnormal behavior.

By implication, color patterns with the characteristics of advertisement are used for intra- and/or interspecific communication. The color patterns, when combined with the specific modal action patterns, produce the elements of the visual communication system utilized by Herotilapia. The color patterns correlate strongly with motivational state. Therefore they may carry important predictive information about the behavior of the individual.

\section{Social Behavior}

Herotilapia is a pair bonded substrate brooder, as are most of the New World cichlids. Its life history includes schooling, $\hat{\theta}$ intraspecific territorial defense of the future spawning site, a prolonged pair bond with a prespawning courtship phase, and joint parental care of the young. The complexity and variety of the social interactions alone make Herotilapia an animal well worth studying. It is also a fish that is adapted to breeding in high density in small ponds, and its aggressive behavior is highly ritualized. This, together with its moderate size, makes Herotilapia an ideal laboratory animal.

Three pairs would breed at the same time in the principal observation tank with little overt physical combat. This made it possible to observe the 
social behavior of the species under conditions in which some variety of mate choice was available and social intercourse with conspecifics was relatively unrestricted. Thus the observations are not limited to arbitrary dyadic interactions.

\section{The School}

Approximately 35 Herotilapia adults were accidently released into a large heated outdoor pond $(11 \mathrm{~m} \times 6 \mathrm{~m})$ populated primarily by Tilapia mossambica. The Herotilapia showed schooling behavior, moving in groups of 2 to 12 individuals, but most commonly 5 or 6. Usually one or two fish were in the vanguard, the rest following in a stretched-out ellipse. Each fish was behind and to the side of the one that preceded it, with about $10 \mathrm{~cm}$ separating the individuals.

The predominance of visual cues in mediating schooling behavior in fishes is generally accepted (e. g. SHAw 1970). Herotilapia follows this rule, as may be inferred from the adoption of a special 'schooling' color, the Two Spot pattern (see Color Patterns). Spots 1 and 5 dominate this color pattern, and they are placed where they emphasize the normal swimming motions of the fish. KEENLEYSIDE (1955) has discussed the importance of such motion emphasizing signals in the schooling characid fish Pristella riddlei. SHAw and Tucker (1965) noted the similarity between the optomotor response of a fish and its behavior in a school. Simple color patterns with conspicuous reference points (such as the Two Spot pattern) could serve to enhance this effect, and hence help coordinate the group's swimming movements.

The fry school differently. The school is much larger, having up to 1500 or more individuals. No color changes were observed. The fry all have the same color pattern whether they are with the school or not. They seem to interact and orient with respect to the school as a whole, although nearestneighbor interactions are evident. Fry on the periphery are constantly turning back and heading into the densest part of the school. The parents also act as a focus for the school. The densest part of the fry school is usually under and slightly behind the pelvic fins of the adults.

Fry raised in a tank with their parents as the only large fish present show poorly developed schooling behavior. The school is diffuse, with little or no coherence.

If the fry are raised with their parents but other adult Herotilapia or 'predator' fish species are present, the school packs near the parents. The school also tends to show uniform orientation when swimming, and stragglers are rare. This phenomenon will be discussed further under the heading of Parental Care.

\section{Territoriality}

Given a reasonable food supply and an adequate breeding site, Herotilapia promptly gives up schooling and starts breeding. There appears to be no obvious seasonal influence, since one pair will produce brood after brood indefinitely, unless they are starved or otherwise disrupted.

If well fed $\delta \hat{\delta}$ and $\not Q T$ are placed in a large aquarium containing many rocks or shelters, schooling wanes with the initial fright response. After a few hours aggressive interactions become apparent. At first the aggression is indiscriminate and does not seem to have anything to do with territoriality. However, after a day or so one or more of the $\delta \hat{\delta}$ starts excluding the other fish from a large area of the tank bottom. Soon each area shrinks, coalescing around some topological feature of the substrate, usually a conspicuous rock. This becomes the focus or core of the territory. Aggressive encounters between $\delta \delta$ with adjacent territories are initially vigorous, but the severity of the 
encounters soon declines as the borders are established. These borders are usually based upon topological features.

A ripe $Q$ will set up a territory if no $\delta$ in spawning condition is present to challenge her. It is likely that this situation is rare in nature: A $q$ requires more energy to get into spawning condition than a $\hat{b}$, due to the large energetic cost of producing eggs. Hence, all else equal, the $\hat{\delta} \hat{t}$ would probably establish territories before the $q O$ are ready to spawn. However, field observations on Cichlasoma nigrofasciatum have shown the $9+9$ to initiate courtship, and joint establishment of the territory by the pair (J. Meral, pers. comm.). It is possible that Herotilapia behaves similarly in the field, and that the above observation of solitary $\delta \hat{\delta}$ initiating territorial behavior is a laboratory artifact.

Herotilapia, like most cichlid fishes, is an aggressive defender of its territory. This can best be studied by dividing the territorial aggression into two stages.

1. Pre-site-attached phase:

During this stage the fish defend no specific area or site within the tank, but schooling behavior has broken down and aggressive encounters are common. The behavior resembles the establishment of a dominance hierarchy.

The Ground Color at this time is a muddy yellow rather than the bright yellow that will appear later. Encounters typically start off with the Shaded Spots pattern and a Lateral Display, or Tailbeating (often accompanied by the Barred pattern). This can quickly escalate into Snapping and such mutual maneuvering as encircling or carouselling (BARLOw 1962), involving the Barred color pattern. Jawlocking, Ramming, Biting and Chasing occur in well developed encounters. During this phase Frontal is seen rarely, and mostly in $q Q$.

\section{Site-attached phase:}

This corresponds to the classic concept of territorial behavior. The $\hat{\delta}$ defends a specific area with oriented displays or overt attacks. The vigor of defense increases as the center or core of the territory is approached. An affinity for a particular portion of the tank is apparent.

In the early stages the $\delta$ attempts to exclude all other fish from a large area. Conspecifics, especially other $\delta \hat{\delta}$, are attacked with more vigor and from a greater distance than are non-cichlids. At first the borders between the territories held by adjacent $\delta \hat{\delta}$ are vague, and violent fights may occur along these marches. These fights are similar or identical to those that occur in the presite attached stage.

The borders are quickly firmed up and become distinct. As this occurs, Snapping becomes infrequent and is replaced by Frontal combined with Stationary Swimming and Exaggerated Swimming. Jawlocking and other overt aggressive acts remain in the repertoire, but their occurrence is less frequent. Tailbeating and Lateral may occur at the boundaries. Once the boundaries have become stable, one can observe one of the most remarkable aspects of cichlid behavior. This is the mutual behavior exhibited by neighboring territorial fish, which NeIL (1964) called 'Pendeling'. The fish threaten each other by alternate charges and retreats, treating the border between them as if it were a transparent wall. Another mutual action engaged in at the border is Parallel-Running (BARLOw 1962), where the fish perform Exaggerated Swimming parallel to each other along their mutual border. The Shaded Spots pattern is commonly assumed during the above action patterns, although the Barred pattern may appear during a particularly intense encounter.

Other action patterns also occur at this time. The Stripe Color Pattern is assumed in the Standing Display, during which the fish hovers with all fins 
spread over the core of his territory. The fish spends much of his time in this position. This appears to be a 'broadcast' display. Digging is also performed at this time. This activity is usually confined to one spot, at or near the core of the territory. It frequently follows an aggressive encounter at the border of the territory, after which the 'winner' or both contestants dig actively at their core areas, swim a short distance toward the opponent's territory, and spit out gravel in his direction. This may be followed by a Frontal Display by the digging fish.

After pair formation, the $q$ joins the $\hat{\partial}$ in defense of the territory. The $q$ at this time shows the Frontal Display as almost her only aggressive display. Overt acts such as Ramming, Jawlock, etc., are commonly used by paired $O O$. After pairing, the $\hat{\delta} \hat{\delta}$ also seem to engage in Frontal Display more than before.

The defense may be joint, or shared. That is, the $\delta$ and $q$ may defend the border of the territory together or may take turns. Commonly, when feeding or during low intensity encounters, the fish take turns on 'guard duty'. If a serious territorial threat occurs, both fish defend the border. Often two pairs encounter each other along their common border. The pendeling that results usually sees the $q$ line up against the $q$, and the $\delta$ against the $\delta$.

The territorial phase lasts through spawning and up until the fry are free-swimming. After spawning the defense of the territory by the parental fish becomes extremely intense, and the Frontal Display with Shaded Spots is almost the only territorial display seen. Overt attacks are directed toward anything that crosses the territorial boundaries.

Territories are usually established by the $\delta \hat{\delta}$ within three days after being placed into an aquarium. Three $\delta \hat{\delta}$ and three $\phi$ were placed into a 2601 tank at 17:00 hrs. At 10:00 hrs. the next morning the fish were observed for $15 \mathrm{~min}$; the number of attacks initiated, the sex of the initiator, and the sex of the receiver were recorded. At 11:00 hrs. and 16:00 hrs. the $15 \mathrm{~min}$ observation was repeated. The results of all three periods were summed. This process was repeated on the following two days as well.

Attacks were classified as the action patterns Biting, Chasing, Ramming, Jawlock, Snapping, Tailbeating and Frontal. These are either overt aggressive acts or are commonly followed by such acts. Only the initial act of an aggressive encounter was scored.

For the purposes of statistical analysis, the Chi-square test was used with the hypothesis that the attacks evenly distributed between $\delta \hat{\delta}$ and $q Q$ (Table 1 ).

Table 1: Attacks initiated by $\hat{\phi} \hat{\phi}$

\begin{tabular}{|c|c|c|c|c|c|}
\hline \multirow{2}{*}{ Day } & \multicolumn{5}{|c|}{ Fish Attacked } \\
\cline { 2 - 7 } & $\sigma^{n}$ & 9 & $N$ & $X^{2}$ & $\mathrm{~N}<$ \\
\hline 1 & 79 & 81 & 160 & .01 & .975 \\
2 & 54 & 74 & 128 & 3.12 & .10 \\
3 & 46 & 68 & 114 & 4.24 & .05 \\
\hline
\end{tabular}

On Day One there was no significant difference between the sex of the fish attacked in aggressive encounters initiated by $\hat{\partial} \hat{\delta}$. The $\hat{\delta} \hat{\delta}$ appeared to attack whichever fish was nearest during this first day.

By Day Two there was a change in the pattern of attacks. The of were starting to show preferences for different areas of the tank. Concurrently, the $\delta \delta$ initiated slightly more attacks on $O+q$ than on $\delta \hat{\delta}$ (but p only .10).

At Day Three at least two of the $\delta$ were clearly territorial. The $q+$ received significantly more attacks from the $\delta \hat{\delta}$ than did other $\delta \hat{\delta}$. The $\delta \hat{o}$ tended to stay within their territories. The $q+q$ roamed about, and thus ran a higher risk violating a territory and of being attacked. 
Table 2: Attacks initiated by $ㅇ$

\begin{tabular}{|c|c|c|c|c|c|}
\hline \multirow{2}{*}{ Day } & \multicolumn{5}{|c|}{ Fish Attacked } \\
\cline { 2 - 7 } & $\sigma^{4}$ & $q$ & $N$ & $x^{2}$ & $p<$ \\
\hline 1 & 26 & 46 & 72 & 5.54 & .025 \\
2 & 30 & 22 & 52 & 1.22 & .50 \\
3 & 22 & 19 & 41 & .20 & .90 \\
\hline
\end{tabular}

Significantly more $q+q$ were attacked by $q \circ$ on Day One than were $\delta \hat{\delta}$ (Table 2). $q O+$ tended to behave on the first day much as did the $\hat{\delta} \hat{\delta}$. They attacked nearest neighbors. However, the $q+q_{\text {were }}$ uniformly smaller than the $\hat{\delta} \hat{\delta}$, and as BARLOw (1970) has suggested for cichlids where size usually determines dominance, size can be equated to potential for attack. Thus, it may be that the $P Q$ were not attacking each other more, but were attacking the $\hat{\delta} \delta$ less, due to inhibition of attack because of the larger size of the $\hat{\delta} \delta$. But examine the attack data for Days Two and Three. There is no significant deviation from chance in the distribution of attacks initiated by 우오 $0 \hat{\delta}$ were more aggressive than $q O$ throughout the early territorial and courtship phases of the reproductive cycle (Tab. 3 ).

Table 3: Totals of attacks initiated

\begin{tabular}{|c|c|c|c|c|c|}
\hline Day & By ơ & By $q q$ & $\mathrm{~N}$ & $x^{2}$ & $\mathrm{p}<$ \\
\hline 1 & 160 & 72 & 232 & 33.36 & $.001^{*}$ \\
2 & 128 & 52 & 180 & 32.08 & $.001^{*}$ \\
3 & $\frac{116}{402}$ & $\frac{41}{165}$ & $\frac{155}{567}$ & 34.38 & $.001^{*}$ \\
Total & \multicolumn{1}{|c|}{} & & 99.06 & $.001^{*}$ \\
\hline
\end{tabular}

* Significant

Both within each sex and collectively, there was a general decrease in the number of attacks across days. A large portion of the decrease may have been due to habituation of aggressive interaction of the sort described by PeEke et al. (1971) for the cichlid Cichlasoma nigrofasciatum. Some of the decrease may also have been accounted for by the increasing site attachment of the $\hat{\theta} \hat{o}$ (see above).

There was also a decline in overt aggressive acts during this interval, with an increase in covert behavior with a high aggressive valence, such as Frontal.

Signal Action Patterns such as Snapping and Frontal were classed as having the highest aggressive valence because they involved an orientation in which the acting fish faced another individual. From such an orientation, overt aggressive acts such as Ramming and Biting were mounted. Thus the most intense mutual aggressive encounter between two fish involved Jawlocking, since both fish have assumed a Frontal orientation with respect to each other and have attacked.

Ramming and Biting are not delivered randomly to the body of the receiving fish, but commonly occur in certain regions. Spots 1 and 5 are common targets for both Biting and Ramming. Biting also occurs on all fins. Ramming is often directed to the head region, especially in encounters between the sexes. The most common targets are the gill cover below and behind the eye, the Solid Stripe where it crosses the gill cover, and the region near the Ocellus, in that order. 
Although much ritualization is evident in the aggressive behavior, it is nonetheless effective. When 18 young adult Herotilapia were held in an 801 tank containing one rock and a bare glass bottom, one pair managed to hold a tiny territory, spawn, and raise the fry to the free swimming stage under these incredibly crowded conditions.

\section{Topographic and Spatial Aspects}

The territories have a characteristic spatial organization. There is some centrally located focus which is a conspicuous topographical feature. In aquaria, this was a large rock resting on the bottom, typically with a cave near by. A rock with vertical sides, and a piece of slate leaning against it to form a shelter, was preferred. Much of the initial aggression in $\hat{\delta} \delta$ seemed to be over such topographic features. The $\hat{\delta}$ who was dominant in these fights usually took the 'best' site for his territory.

At first, only the dominant $\delta$ might hold a territory, attempting to defend the entire bottom of the tank. However, if additional core objects are present, the other $\hat{\delta} \delta$ soon press back the dominant $\hat{\delta}$ until they too hold territories. If the dominant $\hat{\delta}$ holds the only suitable rock, no further territories are likely to be established. In rare instances, however, a second $\hat{\partial}$ may establish a territory even under this condition.

The size of the territory can vary widely depending on the bottom area, the number of adult $\hat{\partial} \hat{\delta}$, and the geography of the tank bottom. In general, the more rocks and hides present, the more territories can be squeezed in. In a large tank $(2601)$ with only one rock, a large $\delta$ or a pair can hold a territory as large as $60 \mathrm{~cm}$ in diameter against 4 other fish. The same tank having three well spaced rocks, and appropriately placed boundary markers, can accommodate three breeding pairs each with a territory $30 \mathrm{~cm}$ in diameter. In the extreme case cited earlier, of the pair breeding in the crowded 801 aquarium, the territory was less than $20 \mathrm{~cm}$ in diameter.

Nor does the size of the territory remain constant throughout the reproductive cycle. The territory contracts somewhat after spawning, while eggs and wrigglers are being cared for. Presumably this is because the performance of parental duties such as fanning makes joint territorial defense difficult. The territory expands once again when the fry become free-swimming.

A factor not often considered in the discussion of territoriality in cichlid fishes is the ability of the fish to modify the topography of the territory. Digging undoubtedly helps render the core more conspicuous and more suitable as a focus for site attachment. It can also function in the establishment and the maintenance of boundaries. Where natural boundary markers are lacking, oriented digging by the $\hat{\delta} \hat{t}$ (as described earlier) tends to build up a mound of gravel along the common border, thus providing a geographic feature where none existed previously.

\section{Courtship}

The territory, once established, becomes the site of courtship activity. The $\delta$ engages in the Standing Display over the core object of his territory, adopting the Stripe pattern. At intervals he makes an abrupt, jerky turn and swims a little loop in Exaggerated Swimming with all fins spread. The loop is swum within the territory and returns him to Standing over the core object.

When a fish approaches the border of a $\hat{\delta}$ 's territory, the $\hat{\delta}$ swims out at the intruder. He swims in front of the other fish while performing Lateral Display and Jerking (Stripe pattern). If the intruder is a ${ }^{*}$, Jerking is rarely shown. A male intruder either responds aggressively (in which case more aggres- 
sive displays soon follow) or backs away. A $q$ may retreat also. If she does not leave, she usually stands. The $\delta$ then circles her and returns to his core object with an Exaggerated Swimming Display. The 9 follows, or remains stationary. If she follows, he performs Nipping, sometimes combined with Quivering, at the core object.

If the $q$ has remained stationary, the $\hat{o}$ turns around over his core object and charges at her. This is similar to Ramming, except the charging $\delta$ stops just short of striking the $q$, and delivers either an open mouth Push to her side or a Frontal Display. The $q$ then assumes the Pitch-Up posture with Shaded Spots. All fins are spread, and she usually Quivers. (A subordinate $\hat{\sigma}$ in a similar situation will also assume the Pitch-Up posture, but with folded fins, the Pale color pattern, and without the Quiver.)

The $\delta$ then returns to his core object, and the $q$ follows or remains nearby. The $\delta$ has the Stripe color pattern throughout this period. Once the $q$ has been engaged by the $\delta$ she wears the Shaded Spots pattern. This is especially true of the smaller, younger $q+$.

After the $q$ has entered the territory of the $\hat{\delta}$, she usually Stands above and to the side of the core object. The $\hat{O}$ may respond with spectacular bouts of Quivering while Digging and Nipping. These bouts commonly alternate with charges and open-mouth Pushing at the $q$, which she responds to with Tilt and Quiver. Auditory cues may play an important role here, for all these action patterns are associated with specific sounds, as described earlier. Olfactory cues may be instrumental in the identification of sex in this externally monomorphic cichlid. The open-mouth Push gives ample opportunity for gustatory cues. Almost all of these pushes are directed at the gill cover, below and behind the eye.

The $P$ soon switches to head-down Quivering with fins spread, in response to the $\hat{\partial}$ 's pushes, and begins Nipping. Nipping by the $\hat{\delta}$ is of ten indiscriminate and is directed to any portion of the core object. The $P$ confines her Nipping to one area, and shortly the $\hat{\delta}$ concentrates his activities at the same location. $\mathrm{He}$ continues to direct Pushes and even Bites at the $P$, in spite of the mutual Quivering and Nipping.

The turning point in the courtship seems to occur when the $q$ joins the $\delta$ in the defense of the territory. When the two fish together rush out and give Frontal Displays to an intruder, the pair is likely to remain together to spawn. At first after such events of joint defense, the $\delta$ turns and delivers an open-mouth Push to the $q$ after the intruder has retreated. She Quivers in response. Soon this grades into the 'greeting ceremony'.

From this point on the $q$ seems to be firmly attached to the $\delta$. She will defend the territory against all conspecifics, $\delta$ or $q$, although she is more vigorous in her attacks on $q q$. The $\delta$ is more selective. He defends the territory against $\hat{\partial} \hat{\partial}$, but intruding $\phi+\phi$ are treated almost as if he were unpaired and in the early stages of courtship. Thus the $\delta$ does not seem to be strongly attached to the $q$ at this time.

This does not lead to the polygamous situation one might expect because of the paired $q$ 's attacks on intruding $q Q$. The $\hat{\delta}$, while not evicting strange $q+$, does nothing to prevent his mate from excluding them.

The Nipping action pattern, like Digging, is a designator. It probably also serves a synchronizing function, like Quivering, in coordinating the timing of the actual spawning. As spawning approaches, joint Nipping and Quivering bouts become increasingly common and exaggerated. 
During this period the $q$ becomes progressively more aggressive, vigorously defending the territory. Frontal Display with Shaded Spots is almost the only display she uses. She is also increasingly likely to return the Bites of the $\delta$.

A special behavior occurs which is only shown within the pair and persists as long as the pair lasts. This behavior, the 'greeting ceremony', emerges when one member of the pair has been away from the territory (or fry, etc.) and returns. The returning fish swims past the mate that has remained. While passing, antiparallel, the two fishes incline their heads toward each other in a motion that looks like a cross between Jerking and Lateral Display.

Spawning usually happens within two to ten days after the $P$ enters the $\delta$ 's territory. It is preceded by Skimming, which appears a few hours or less before spawning. This action pattern is virtually identical with Skim-Fanning, which will be described in the section on parental behavior. Skimming is performed by the + , and to a lesser extent, the $\hat{o}$ (see section on Signal Action Patterns). It is possible that chemical cues are deposited.

Skimming may be Skim-Fanning from the parental phase occurring outside its normal context. I have observed fish prior to spawning that picked up gravel, churned it in their mouths and spit it onto a slanted piece of rock. As the gravel rolled down the slope, it was picked up and spit out again higher up. This may be repeated several times. The behavior is identical to the action patterns used in retrieving and plastering the young, which occurs during the parental phase.

Spawning

During egg laying the $q$ is oriented with her ventral surface pressed against the substrate. This is typically the vertical side of a rock near a cave or a tunnel. The posterior portion of the o's ventral surface does not touch the substrate, but is lifted up and away from the substrate, with the anterior portion of the fish canted slightly forward. The pectoral fins are lifted up and back, away from the substrate, and they press the fish against the surface with fluttery movements. The $q$ lays eggs as she moves in slow arcs. The eggs are not laid continuously but in 'runs' which are separated by the $q$ backing away and hovering near the site.

The $\delta$ 's fertilizing movements look like Skimming, except the pectoral fins are held up and away from the eggs, as in the + . The $\delta$ has the Stripe coloration throughout spawning, while the $\&$ shows the Shaded Spots color pattern. The 's iris of ten turns dark during egg laying runs, but rapidly becomes yellow between bouts.

If the pair is alone or undisturbed, the $\delta$ and $O$ usually spawn together on the site, the $\hat{O}$ following the $P$. However, in a tank with other fish the pair frequently takes turns, with one fish guarding while the other spawns. They are extremely aggressive at this time, and keep other fish well away from the spawning site.

The end of spawning is signaled by the change from the action patterns of egg laying and fertilizing to those of Skim-Fanning. A typical spawning may take 2 hrs and produce 500 to 1500 eggs. Fertility is greater than $90 \%$.

\section{Parental}

The parental phase starts with the care and defense of the eggs immediately after spawning. On the second day after spawning the eggs hatch. The wrigglers (larvae) are not yet free-swimming; they still have a large yolk sack, an adhesive gland, and are not completely developed. Four to five days 
after hatching they become free-swimming fry. The parents remain with the fry four weeks or more. These developmental stages provide convenient categories for analysis.

Eggs

After spawning, the eggs become the center of attention and defense for the Herotilapia pair. Their aggressive behavior toward other fish grows more determined. Intruders are met by Frontal Displays and charging, and the parents tend to show the Shaded Spots pattern all the time. The $O$ is especially aggressive. She will allow the $\delta$ to approach the eggs only at rare intervals on the day of spawning and much of the following day. The $\hat{\theta}$ spends this brief period of 'banishment' near the spawning site and within the territory, which he continues to defend zealously.

This exclusion of the occurs in the community tank situation where other pairs are present. In an isolated pair the $q$ permits the $\delta$ to have access to the eggs, and Fanning bouts are alternated between $\delta$ and $q$. BuTz and KUENZER (1957) reported a similar pattern of behavior in the two dwarf cichlid species Apistogramma reitzigi and Nannacara anomala. However, the period lasts only one or two days in Herotilapia, as opposed to a much longer period in those two species. If the + Herotilapia is removed, the $\hat{\delta}$ becomes the caretaker of the eggs.

The most conspicuous response to the eggs is Fanning. There are two recognizable types:

1. Skim Fanning. This is identical to the Skimming action pattern described previously, and is directed to the eggs resting on the substrate. This action pattern is commonest right after spawning, and disappears after the fry hatch. The $Q$ Skim-Fans more than the $\delta$.

2. Hover-Fan. The fish hovers about $2 \mathrm{~cm}$ away from the eggs and orients with one side toward the eggs. The pectoral fin on the side facing the eggs fans water toward them. The fish is usually oriented head up, with fins at least partially spread. This type of fanning is rare immediately after spawning, but becomes commoner as hatching approaches.

Both types of Fanning exhibit about the same tempo (ca. 2 beats/sec, twice the tempo for relaxed hovering). Skim-Fanning is commonest in undisturbed pairs alone in a tank. Hover-Fan is commonest in community aquaria. Hover-Fan appears to be a compromise between the Standing Display and Fanning.

Along with the increasing aggression against conspecifics, there is an even more marked increase in aggression against other species. Indeed, the most vigorous attacks delivered by the pair tend to be toward fish species which previously were ignored or received only token chases.

A behavior that becomes increasingly common as hatching approaches is mouthing of the eggs. This behavior resembles Nipping, except it is directed specifically at the eggs. Fungused eggs are eaten (these were identified by their whitish appearance). It is likely the fish is receiving chemical cues or testing the egg membranes by such behavior, thus gaining information of the probable time of hatching. When hatching occurs, the fry are 'chewed' out of the rather tough egg membrane by the parents.

\section{Wrigglers}

As the wrigglers hatch, they are immediately moved by the parents to one of a number of pits that they have previously dug within the territory. These pits are usually placed against some object, and are about $5 \mathrm{~cm}$ deep and $10-15 \mathrm{~cm}$ across. As the wrigglers are spit into the pit they swim in a spiraling dive to the bottom. They are rarely placed in a pit near to the spawning site. 
The parents Hover-Fan over the wrigglers for the next few days, but this behavior becomes increasingly infrequent. The wrigglers may be moved several times in the next four days before they become free-swimming. At this time the Shaded Spots color pattern on the parents is becoming dark.

If the bottom of the tank is covered with detritus, the parents may 'plaster' the wrigglers on a vertical surface: The wrigglers are taken into the mouth and spit at the surface in question. They adhere to this spot by the adhesive gland on their foreheads. If they fall off, they are retrieved by the parents and spit back into position. Plastering behavior was rarely seen.

\section{Fry}

Caring for the free-swimming fry is the final stage of the parental cycle. It is also the longest. Parental care of the fry can last four weeks or more, and the pair bond usually persists throughout.

The fry do not all become free-swimming at the same time. Several may be seen to be hopping, struggling to swim up off of the bottom, in the late afternoon. The parents take these fry into their mouths and spit them back into the pit. By the next morning all the fry are free-swimming, but they are in one mass, filling the pit to its brim and not leaving the immediate area. As stragglers stray out over the rim of the pit, they are retrieved by the parents and placed back into the mass. By midmorning the fry are more spread out and are exploring the immediate area of the pit. The parents make frantic efforts to return the fry to the pit, but the task is hopeless and they soon give up. Thereafter they only prevent the fry from straying too far from the main school. Now the school leaves the pit and the individual fry may be seen to be feeding. The school is compact and well organized for the first two days, regardless of the presence or absence of predators in the tank. For the first couple of weeks after they are free-swimming the parents gather the fry into a pit every night where they are bedded down.

The parents seem to have little or no specific control over the movements of the fry school. There is one action pattern the parents perform, however, that the fry seem to respond to. This is Jolting, described earlier. I was unable to determine if a sound is associated with Jolting, but it seems likely that a substantial near-field effect must accompany such a sudden movement. The fry respond by swimming to the parents and down toward the substrate. As the parents back away from the disturbing stimulus the fry follow and bunch up under them.

When the fry become free-swimming the parents assume the Mitschattierung color pattern, which they retain as long as they guard the fry.

The fry seem to stay nearest the area of the pelvic fins on the ventral surface of the adults. Fry that have been free-swimming for more than a few days avoid the head region of their parents. When a parent attempts to take a straggling fry into its mouth, the fry shows fright behavior. It flees from the parent in quick darts that often take it back into the school of fry.

Once the fry are free-swimming, the $q$ becomes less aggressive toward her mate. Both fish become more aggressive toward other fish. The aggression is no longer strictly territorial, however. An approach distance of about $20 \mathrm{~cm}$ from the school of fry becomes the focus for the defensive activity. All aggression is vigorous and is oriented relative to the school. The adults and fry roam the tank, and the parents are aggressive enough at this time to encroach on the territories of other pairs. The presence of fry in a tank thus promotes heightened aggressive encounters between pairs. As a consequence the fre- 
quency of Jawlocking goes up. In such encounters, the pairs usually face off by sex.

In encounters between two pairs with fry, the two schools of fry often come close to one another. When the parents start Jolting and threatening, the fry tend to flee to the nearest school of fry and set of parents. Sometimes this results in the fry joining the wrong school. In every case where this was observed, the new fry were accepted by the school and by the parents, except when the new fry were more than a few days older than the school they were cntering. Then the new fry were usually chased out of the school by the parents. Rarely were they caught and eaten. In one remarkable instance, in which three pairs spawned within a week in a large tank, one especially aggressive pair had all the fry in their one school after four weeks. They were not observed to have eaten any of the young they were guarding.

In another instance, two pairs spawned in the same tank about $6 \mathrm{hrs}$ apart. At the end of a week, the fry of Pair One (the first pair to spawn) had just turned free-swimming and were hovering in the pit. The wrigglers of Pair Two were at the hopping stage. The $\delta$ and $q$ of Pair Two were then removed from the tank, during which many of their wrigglers were scattered outside the nest. Immediately after the removal of Pair Two, the adults of Pair One swam over and investigated Pair Two's pit. They immediately ate the wrigglers inside the pit and around its rim. However, the wrigglers outside the rim were scooped up and carried back to their own pit where they were spit into the school of fry. Thus spatial location, topography, and context have a great deal to do with identification of young in Herotilapia. Weber (1970) has demonstrated the importance of these factors in the egg-care behavior of Cichlasoma nigrofasciatum, just as others have suggested the importance of such cues as specific odor and visual identification (GREENBERG 1963; KüHME 1963; MYRBERG 1961, 1964, 1966).

A Herotilapia- 9 can produce a new batch of eggs within 10 to 14 days after spawning, if the previous eggs are removed immediately. Since this does not normally occur during parental care, the presence of the fry must inhibit egg production. Twice, however, pairs with fry spawned. When this occurred, two types of behavior were seen. In the first, all the previous fry (14 days old) were eaten within $12 \mathrm{hrs}$ after spawning, after having been chased away from the spawning site. In the second, the previous fry ( 28 days old) were ignored when they approached the spawning site, and they picked at the eggs while the parents were fanning them. The fry ate all the new eggs within $24 \mathrm{hrs}$, after which the parents went back to guarding their cannibalistic offspring.

Gerald Meral (pers. comm.), who has done a great deal of field observation on Central American cichlids, has opined that territoriality and parental care in these species function primarily as a specific adaptation to protect the fry from predation. I performed a crude experiment in the laboratory to test this hypothesis with respect to Herotilapia. A pair was placed into a 1501 tank with a single $14 \mathrm{~cm}$ long Gobiomorus dormitor, an eleotrid fish. This is a common bottom lurking predator of Central America.

When the Herotilapia spawned, the number of the eggs was estimated, then later the number of two-week swimming fry. Then the parents were removed, and the time it took the predator to remove all the remaining fry was recorded. This experiment was repeated, using as the predator three $7 \mathrm{~cm}$ long Astyanax faciatus, a schooling characin.

The results were convincing. The Gobiomorus failed to capture fry when their parents were present. However, it consumed all the fry within $24 \mathrm{hrs}$ 
after the parents were removed. The Astyanax were more effective, but at least $25 \%$ of the original number of fry remained after two weeks. The Astyanax consumed these within 12 hrs after the removal of the parents.

The adults did not react in the same manner to all types of potential predators. Cichlid type fish were usually challenged with a Frontal Display, while fish which departed markedly from the basic cichlid shape, such as Gobiomorus or Astyanax, were more apt to suffer direct attack. Rapidly swimming schooling predators, such as Astyanax, were driven off when they approached too closely, but were rarely chased for any great distance. Lurking predators such as Gobiomorus were attacked and chased throughout the tank. A male Herotilapia protecting fry will literally hound to death a Gobiomorus twice his size in the confines of a 1501 aquarium, unless the Gobiomorus is provided with a shelter that only his elongate form can utilize. The parents are obviously effective defenders of their fry.

\section{Discussion}

In any signal system, the transmitting characteristics of the medium and the limitations of the receptor determine the characteristics of the ideal signal (MARLer 1969, Konishi 1970). As was pointed out, cichlid fishes are visually oriented. Therefore we have to consider the visual properties of the environment of Herotilapia.

The normal medium in which Herotilapia breeds is turbid water. LuRIA and KINNEY (1970) reported that peak transmission of light through water shifts toward the long wavelengths as turbidity increases, with maximum transmission occurring in the yellow-red region. The colors yellow and orange had the highest visibility to human divers in turbid water. These colors also proved to be the easiest to identify correctly. Since freshwater fish have a visual action spectrum similar to that of humans, it is reasonable to assume that Herotilapia also sees these colors best in turbid water.

The color patterns used by Herotilapia during reproduction are doubtless adapted for visibility in a turbid environment. The bright yellow Ground Color of the Stripe pattern is unusual for a cichlid fish. The flashing iris and dark pupil of the eye are not obscured by any markings, but are followed closely by the sharp bordered Lateral Stripe which contrasts abruptly with the Ground Color. The entire pattern is dramatic, and conspicuous elements are emphasized rather than concealed (BARLOW 1972).

If the color patterns are indeed signals, some form of information must be conveyed from sender to receiver. The color patterns of Herotilapia can all be assigned to one or more of the message sets proposed by SMITH (1969). The Stripe pattern for example is simple, dramatic and structurally species specific, an ideal signal for species identification. However, this is probably not the most profitable approach to defining the role of the color patterns in the Herotilapia signal system.

The color patterns seem to be used to identify which behavioral set the individual is operating in. Adult Herotilapia have three major social roles, each of which is characterized by particular patterns of behavior. Each role is associated with a specific color pattern, which is a signal that provides other fish with information on what general classes of behavior may be expected from the individual. Thus the Two Spot pattern is associated with schooling, 
the Stripe pattern with territorial and sexual behavior, and the Mitschattierung with parental care and defense.

These three color patterns show 'typical intensity' (MorRIS 1957). This may be a consequence of the importance of the signals and the resultant need that they be unambiguous, and/or it may be a consequence of the poor signal transmitting characteristics of the fish's environment.

One color pattern is predictive in the more immediate sense of motivation. This is the Shaded Spots pattern which overlays the Stripe pattern. The darkness of the Shaded Spots pattern is directly proportional to aggressiveness in territorial fish, and thus shows a graded response. As MARLer and Hamiton (1966) have pointed out, this is typical of aggressive displays. Also typical of graded signals, they occur only when the individuals are in close proximity.

The Signal Action Patterns are predictive in the same sense. They provide the immediate context of the behavioral situation, and thus give cues to the probability of certain following acts occurring.

As APFELBACH (1969) has pointed out, substrate brooders and mouthbrooders cannot be divided along monomorphic and dimorphic lines respectively. However, his data suggest that the monomorphic/dimorphic division does apply to the degree of sexual role specialization in reproduction and parental care. Those Tilapia with the more specialized sexual roles are dimorphic. This also applies to the different evolutionary paths followed by the social systems of the New World cichlids as opposed to the African species. Where Old World cichlids tend to show a specialization in terms of sexual roles in parental care, the New World species are inclined to have complete interchangeability of sexual roles with respect to parental care. This is reflected in the tendency for the New World cichlids to be monomorphic. In this respect Herotilapia is a typical New World cichlid.

A fundamental problem faced by a monomorphic, pair bonded cichlid species is the regulation of overt aggressive behavior within the pair. This is especially a problem in a species such as Herotilapia, where the $q$ is smaller than her mate. This problem seems to be handled in Herotilapia by the $q$ adopting signals associated with aggressive intent. For example, a $q$ confronted by a $\hat{o}$ shows the Tilt posture with spread fins and the Shaded Spots pattern. This display contains elements of both threat and appeasement. A $\delta$ in the same situation would only Tilt with folded fins. Throughout the pair bond the $q$ manifests both Color Patterns and Signal Action Patterns with a higher aggressive valence than those shown by her larger mate.

These signals may be called appeasement behavior, as they are ". . signals reducing the probability of attack", (BARLOw 1968). I disagree with this definition, as the connotation of appeasement is 'to yield to avoid conflict'. I think this behavior might better be called threat, 'to appear dangerous'.

I do not think the point is merely semantic, as the manner in which the probability of attack is reduced is different, as BARLOw (1968) indicated. As a consequence, the probability of following action patterns occurring is different in the two situations. The different effects of threat and appeasement signals on subsequent behavior have been demonstrated by DuNHAm et al. (1968) in Barbus stoliczkanus.

A further consequence of pair bonding is the need for individual recognition. Pair bonding presupposes that one is able to recognize one's own mate. Noble and CURTIS (1939) demonstrated that the head is the most important region for individual recognition in another cichlid, the African jewel fish (Hemichromis bimaculatus), and this may be true for vertebrates in general 
(MARLER 1961 a). Herotilapia shows a great deal of variation of markings on the head. The markings on opposite sides of the head are asymetrical, and the irregular borders of the portion of the Solid Stripe on the gill cover varies among individuals. There is also variation in eye color, some fish showing a bright red iris. This should provide ample cues for individual recognition.

The tendency of pairs to line up sex against sex along contested borders may also be a consequence of the pair bond. I suspect this is due to the opposite sex resembling one's own mate more, and thus inhibiting attack. The uniformly larger size of the $\delta \hat{\delta}$ may have a general inhibitory effect on attacks from the + iq.

If we accept the hypothesis that parental aggression is an adaptation to protect fry from predation, how are we to explain the fact that the $\delta \hat{\delta}$ are aggressively territorial even before they are paired? Territorial behavior is usually associated with some defensible resource limiting on the species. Where is the limiting resource in this instance?

There are in fact two answers. One, not all sites are equally suitable for spawning. Two, not all sites are equally defensible from predation.

The clues to the answers lie in the selective manner in which the $\delta t$ establish their territories around a core object, and the type of location the $q Q$ choose to spawn on. Spawning almost always takes place on a vertical surface, where little silt could settle on the eggs. The preferred core object is more easily defended because predators can approach from one direction. The territories can be a limiting resource for Herotilapia, because they may affect the number of offspring surviving. Thus it is in direct relationship to a specific sort of prominent object that site attachment occurs. One might almost predict that the ease of eviction from a territory would be inversely proportional to the conspicuousness and suitability of the core object, and not simply a function of dominance, all else being equal.

The schooling behavior of the adults can be related to the need for high vagility. Say we are trying to disperse a species to isolated habitats. If we disperse them as individuals, each individual has a certain probabilty of arriving in a suitable habitat. But the probability of two individuals arriving in the same habitat will be lower, and the probability that the two animals are of the opposite sex will be lower still. However, if we disperse our organisms in randomly composed groups of six individuals each, the probability of a pair being present given they arrive in a suitable habitat will be $1-(1 / 2)^{6}$, a high probability indeed. I doubt that the function of the schooling behavior of the adults is to reduce the chances of predation, as the average group size observed (5-6) would be too small to be effective, although the 'selfish herd' model would fit the fry nicely (HamiLTON 1971).

In fact, the selfish herd hypothesis might explain why the parents are not 'picky' about accepting foreign young. Within reasonable limits, the more fry in a school the less likely it is that your own will be picked off. It may also be that the additional energy cost of caring for foreign young is below the evolutionary noise level, and hence not selected against.

An unusual behavior occurred in the pond. Although they had been kept in a cage for eight months prior to their escape, 13 of the fish jumped out and died in their first two days of freedom. There were no changes in the water conditions at that time, and the fish bore no signs of damage from possible encounters with other fish. All of the dead fish leapt out where water from a filter system pours in at the pool edge as a small waterfall. Evidently, the fish were attempting to move upstream. When a screen was placed over the 
water there, the deaths stopped. Although many Cichlasoma nigrofasciatum were accidentally released at the same time, they did not show this behavior, nor did any of the other cichlid species in the pond.

This jumping behavior might also be a specific adaptation to increase the vagility of the species, although I am hesitant to put much weight on an isolated incident. However, the dispersal power it would give the species in finding suitable habitats isolated from the river is considerable.

The opportunistic strategy of Herotilapia puts a heavy load on the species. The risk of local extinction is high, and the dependence on a dispersal strategy means that many offspring may fail to find a suitable habitat. It also means that relatively few individuals will produce most of the offspring for the next generation. Because of this, there is selection to maximize the number of offspring per pair. It is possible for the fish to breed in high densities in the ponds, because they are shallow and nutrients are concentrated during the dry season. Vegetative growth is profuse, so food resources are probably not critical. What is limiting is space.

Because of selection for breeding in high population densities, ritualized aggression is selected for. Overt aggression is too wasteful of energy and time. Each encounter may weaken the individual and thus increase the probability that he will lose the next encounter. Damage is a great risk in aggressive encounters, especially in turbid water where infection may result.

One consequence of this ritualization has been the evolution of deflective markings (BLEST 1957). Overt attacks are commonly addressed to Spots 1 and 5 , the Ocellus, or the trailing fin margins.

A good strategy to adopt in defense of fry from predators would be to keep the predator as far from the fry as possible, preferably further away than he can detect the presence of the fry. This may be the function of the Mitschattierung color pattern. The conspicuous features of this color pattern have been described earlier. It is a pattern that would be visible for some distance in turbid water. Associated with the Mitschattierung pattern is the extremely aggressive defense of fry by the parents. This could cause the predators in a confined area to associate the Mitschattierung pattern with dangerously aggressive fish and thus avoid their immediate area. Thus the Mitschattierung pattern could have an aposematic function. A further selective advantage may be that it would be harder for a predator to spot the fry when they are silhouetted against a dark belly. Several other species of Central American cichlids develop a dark ventral color pattern during the parental care phase (Cichlasoma macrocanthum, C. spilurum, C. centrarchus), and this may represent a case of Müllerian mimicry.

\section{Summary}

Herotilapia multispinosa is a small cichlid fish native to the coastal lowlands of Central America. It is an opportunistic species whose physiological tolerance allows it to exploit the small bodies of water left by receding floods as privileged sanctuaries. It is in these ponds that most of the breeding activity occurs.

The adults are largely herbivorous and lack specialized prey catching behavior, although such behavior is present in the fry. When given a choice, the adults prefer an omnivorous diet. 
The sexes are relatively monomorphic, and lasting pair bonds are formed. Joint territorial defense and cooperative rearing of young are the rule. Territorial defense is vigorous, but the aggression is highly ritualized so that damaging fights are rare. The territories used for breeding are remarkably compressable, and three pairs could spawn concurrently in a single $260 \mathrm{l}$ aquarium. The territorial behavior is typified by site attachment, and the size and location of the territory depends largely on the availability of core objects.

The yellow and black reproductive color pattern shows a specific adaptation to the fish's normal visual environment. It is a signal ideally designed for conspicuousness in turbid water. The same signal properties are exhibited by the Mitschattierung, or reverse counter shade color pattern assumed by the parents during defense of their young. It is hypothesized that this latter pattern may have an aposematic function.

\section{Zusammenfassung}

Herotilapia multispinosa ist ein kleiner Cichlide aus dem Küstengebiet Zentralamerikas. Diese anpassungsfähige Art kann wegen ihrer großen physiologischen Toleranz Überschwemmungs-Tümpel als günstige Zufluchtsorte erfolgreich ausnützen. Überwiegend hier brütet sie. Die Erwachsenen sind vorwiegend Pflanzenfresser ohne das spezialisierte Beutefangverhalten, das der Jungfisch zeigt, bevorzugen aber Mischkost. Die Geschlechter sind relativ monomorph und gehen eine Brutsaison-Paarbindung ein. Gemeinsame Revierverteidigung und Brutpflege ist die Regel. Revierverteidigung ist deutlich, aber der Kampf ist stark ritualisiert, so daß Verwundungen selten vorkommen. 3 Paare können gleichzeitig in einem 260-1-Aquarium ablaichen. Größe und Lage des Territoriums hängen von auffallenden Objekten ab, um die herum es entsteht. Das Territorialverhalten ist ebenfalls objektbezogen.

Das gelb-schwarze Muster der Fortpflanzungsfärbung ist an die normale Umgebung der Fische angepaßt: es soll in trübem Wasser auffallen. Die gleichen Signaleigenschaften werden zur "Mitschattierung" verwendet, die die Eltern während der Verteidigung ihrer Jungen zeigen. Es wird die Hypothese aufgestellt, daß die „Mitschattierung“ aposematisch wirkt.

\section{Acknowledgements}

I am grateful to George W. BARLow for introducing me to this delightful cichlid; he offered patience, encouragement and advice at all stages of the research and writing. Roy CALDwell and Steve Glickman helped with the manuscript, for which I thank them. I am also indebted to David L. G. NoAKEs, who gave so freely of time and advice. Special thanks are due to Judy Stamps, who prepared the illustrations, and to Catherine BlEIck, who helped make the field collections. William Bussing and Gerald Meral allowed me to inspect their collections and field notes, and offered much advice on the ecology of Central American fishes. Abby SCHWARTZ generously made available her sound-recording equipment. This research was made possible by NSF grant GB 13426 to G. W. BARLow.

I am also grateful to Werner LOHER for preparing the German summary.

\section{References}

Albrecht, H. (1962): Die Mitschattierung. Experientia 18, 284-286 - Apfelbach, R. (1969): Vergleichende quantitative Untersuchungen des Fortpflanzungsverhaltens brutpflegender mono- und dimorpher Tilapien (Pisces, Cichlidae). Z. Tierpsychol. 26, 692-725 - BaErends, G. P., and J. M. BAERENDS-van Roon (1950): An introduction to the study of the ethology 
of cichlid fishes. Behaviour Suppl. 1, 1-243 - Baerends, C. P., R. Brouwer and H. T. WaterbolK (1955): Ethological studies on Lebistes reticulatus (Peters) I. An analysis of the male courtship pattern. Behaviour 8, 249-332 - BARLOW, G. W. (1961): Social behavior of the desert pupfish, Cyprinodon macularius, in the field and in the aquarium. Amer. Mid. Naturalist 65, 339-359 - BARLOW, G. W. (1962): Ethology of the Asian teleost Badis badis. II. Motivation and signal value of the colour patterns. Anim. Behav. 11, 97-105 - BARLow, G. W. (1967): The functional significance of the splithead color pattern as exemplified in a leaf fish, Polycentrus schomburgkii. Ichthyologica 39, 56-70 - BarLow, G. W. (1968): Ethological units of behavior. In: The Central Nervous System and Fish Behavior. D. IngLE (ed.), Univ. of Chicago Press, 217-231 - BARLow, G. W. (1970): A test of appeasement and arousal hypotheses of courtship behavior in a cichlid fish, Etroplus maculatus. Z. Tierpsychol. 27, 779-806 - BARLOW, G. W. (1972): The attitude of fish eye lines in relation to body shape and to stripes and bars. Copeia 1972, 4-12 - BergmanN, H. H. (1968): Eine deskriptive Verhaltensanalyse des Segelflossers (Pterophyllum scalare Cuv. \& Val., Cichlidae, Pisces). Z. Tierpsychol. 25, 559-587 - BLEST, A. D. (1957): The function of eyespot patterns in the Lepidoptera. Behaviour 11, 209-256 - Butz, E., and P. Kuenzer (1957): Zur Brutpflege einiger Zwergcichliden. Z. Tierpsychol. 14, 204-209 - Cотт, H. B. (1957): Adaptive Coloration in Animals. Methuen, London, 1-508 - Dunham, D. W., K. Kortmulder and J. J. A. van IERSEL (1968): Threat and appeasement in Barbus stoliczkanus (Cyprinidae). Behaviour 30, 15-26 - Greenberg, B. (1963): Parental behavior and imprinting in cichlid fishes. Behaviour 21, 127-144 - Günther, A. (1869): An account of the fishes of Central America, based on collections made by Capt. J. M. Dow, F. Godman, Esq., and O. Salvin, Esq. Trans. Zool. Soc. London 6, 377-494 - Hamilton, W. D. (1971): Geometry for the selfish herd. J. Theo. Biol. 31, 295-311 - Hamilton, W. J. (ms.): Coral fish coloration - KeEnLEyside, M. H. A. (1955): Some aspects of the schooling behavior of fish. Behaviour 8, 183-248 - KonisHI, M. (1970): Evolution of design features in the coding of species-specificity. Am. Zoologist 10, 67-72 - KüHmE, W. D. (1963): Chemisch ausgelöste Brutpflege- und Schwarmreaktionen bei Hemichromis bimaculatus (Pisces). Z. Tierpsychol. 20, 688-704 - LeONG, C.-Y. (1969): The quantitative effect of releasers on the attack readiness of the fish Haplocbromis burtoni (Cichlidae, Pisces). Z. vergl. Physiol. 65, 29-50 - Lewontin, R. C. (1965): Selection for colonizing ability. In: The Genetics of Colonizing Species. H. G. BAKER and G. L. STEBbins (eds.). Academic Press, New York, 77-91 - Luria, S. M., and J. A. KinNey (1970): Underwater vision. Science 167, 1454-1461 - MacArthur, R. H., and E. O. Wilson (1967): The theory of island biogeography. Princeton Univ. Press, New Jersey - Marler, P. (1961a): The evolution of visual communication. In: Vertebrate Speciation. F. Blalr (ed.). Univ. Texas Press, Austin - Marder, P. (1961b): The logical analysis of animal communication. J. Theo. Biol. 1, 295-317 - Marler, P. (1969): Visual systems. In: Animal Communication. T. Sebeok (ed.). Indiana Univ. Press, Bloomington, 103-126 - MARLer, P., and W. J. Hamilton (1966): Mechanisms of Animal Behavior. Wiley, New York, 771 - Morris, D. (1957): "Typical intensity" and its relation to the problem of ritualization. Behaviour 11, 1-12 - Myers, G. S. (1966): Derivation of the freshwater fish fauna of Central America. Copeia 1966, 766-773 - MYrberg, A. A. (1964): An analysis of the preferential care of eggs and young by adult cichlid fishes. Z. Tierpsychol. 21, 53-98 - MyrBerg, A. A. (1965): Sound production in cichlid fishes. Science 149, 555-558 - MYrberg, A. A. (1966): Parental recognition of young in cichlid fishes. Anim. Behav. 14, 565-571 - NeIL, E. H. (1964): An analysis of color changes and social behavior of Tilapia mossambica. Univ. Calif. Publ. Zool. 75, 1-58 - Noble, G. K., and B. CurTis (1939): The social behavior of the Jewel Fish, Hemichromis bimaculatus Gill. Bull. Amer. Mus. Nat. Hist. 76, 1-46 - Odiorne, J. M. (1957): Color change. In: The Physiology of Fishes. M. E. Brown (ed.). Academic Press, New York, 2, 387-402 -Peeke, H. F. S., M. J. Herz and J. E. Gallagher (1971): Changes in aggressive interaction in adjacently territorial convict cichlids (Cichlasoma nigrofasciatum): a study of habituation. Behaviour 40, 43-54 - Pellegrin, J. (1903): Contribution a l'étude anatomique, biologique et taxonomique des poissons de la famille des Cichlides. Mem. Soc. Zool. XVI (Paris) 1903, 41-400 - SHAw, E. (1970): Schooling in fishes: critique and review. In: Development and Evolution of Behavior. L. R. ARONSON, E. T. TOBACH, D. S. Lehrman and J. S. Rosenblatt (eds.). Freeman, San Francisco, 452-480 - Shaw, E., and A. TUCKER (1965): The optomotor reaction of schooling carangid fishes. Anim. Behav. 13, 330-336 - SMITH, W. J. (1969): Messages of vertebrate communication. Science 165, 145-150 - Süffert, F. (1932): Phänomene visueller Anpassung. Z. Morph. Okol. Tiere 26, 147-316 - Van Valen, L. (1971): Adaptive zones and the orders of mammals. Evolution 25, 420-428 - WEBER, P. G. (1970): Visual aspects of egg care behaviour in Cichlasoma nigrofasciatum (Günther). Anim. Behav. 18, 688-699.

Author's address: J. R. BAYLIS, University of California, Dept. of Zoology, Berkeley, California 94720 , U.S.A 